تأثير ييشخيرانه عصاره زيره (كومين سيمينوم) بر ميزان حجم باقيمانده معده بيماران ترومايى تحت ونتيلاتور بسترى در بخش مراقبتهاى ويزٌه

سيده ربابه بابايى آبندانسرى'، معصومه باقرى نسامى "*، افثين قلى يور برادرى"، جمشيد يزدانى خراتى"، سيده

ا-ـ دانشجوى كارشناسى ارشد ير ستارى مراقبتهاى ويُّه، كميته تحقيقات دانشجويى، دانشخاه علوم بزشكى

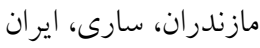

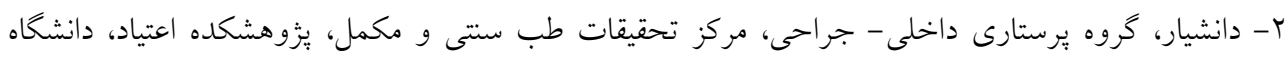

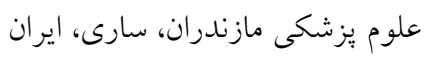

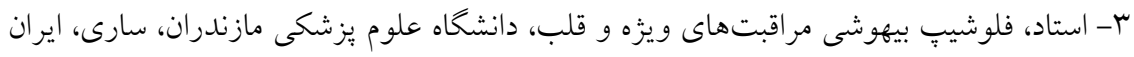

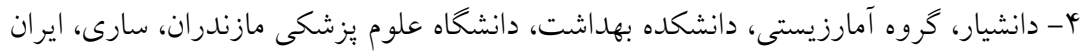

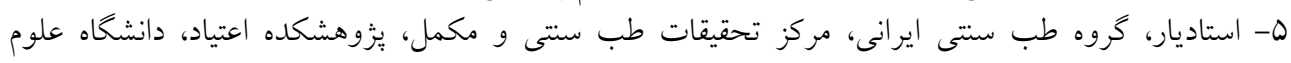

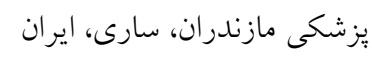

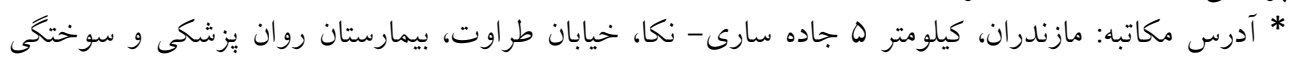

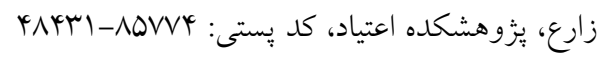

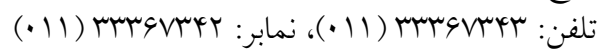
anna3043@gmail.com : بست الكترونيك:

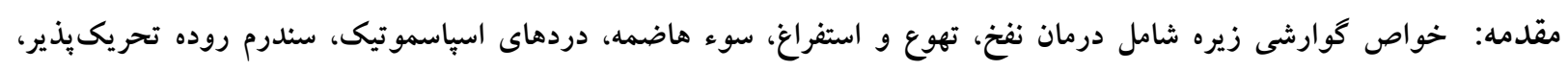

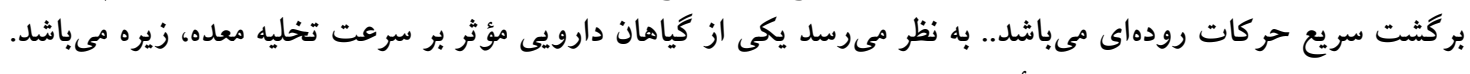

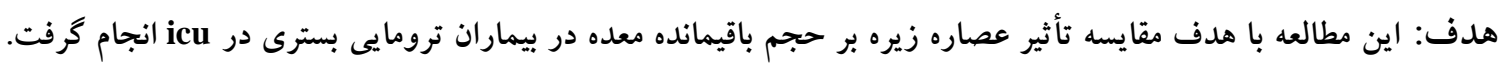

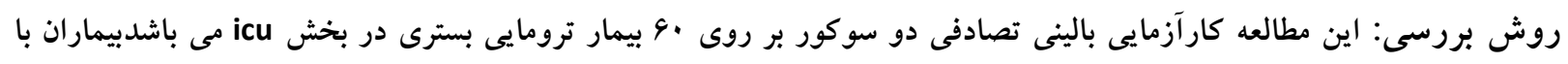

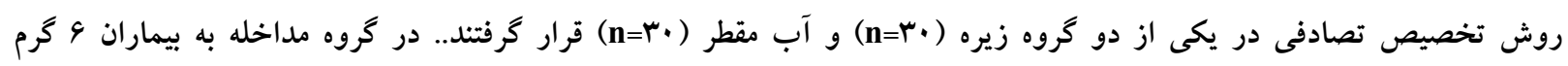

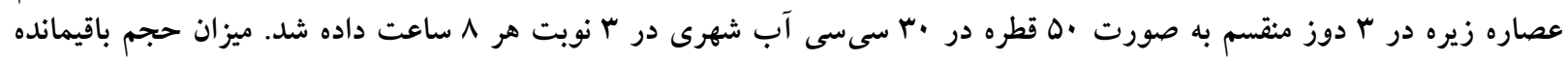

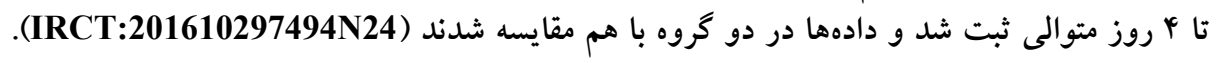

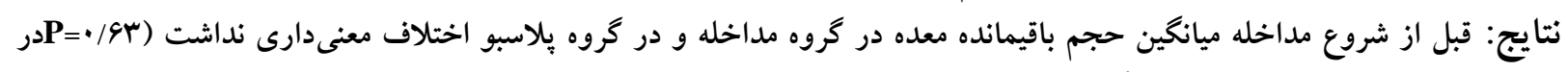

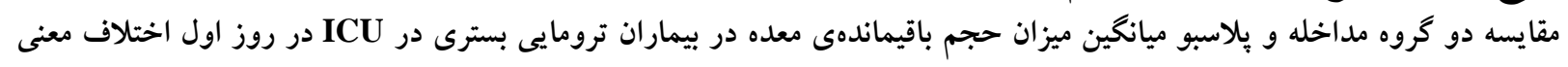

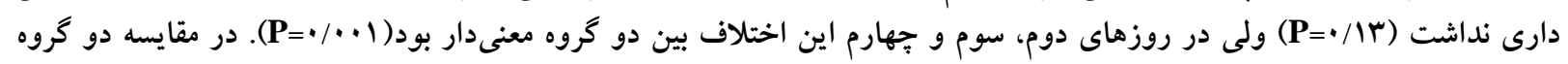

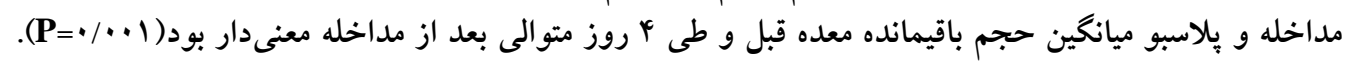

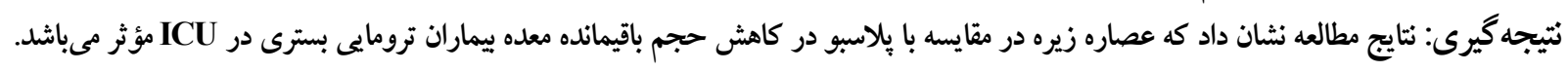
كلوازكان: بخش مراقبتهاى ويزُه، بيماران تحت ونتيلاتور، تغذيه رودهاى، حجم باقيمانده، زيره، لاواز معدى 
بر اين، داروهاى يروكينتيك نتوانستند به طور قابل توجهى

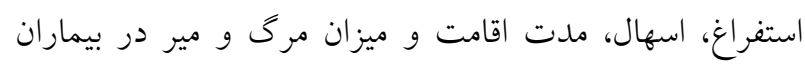

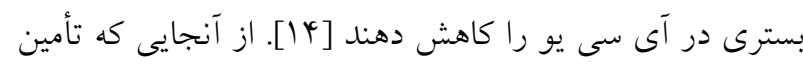

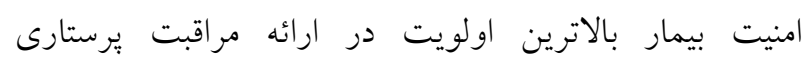

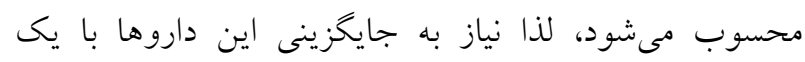

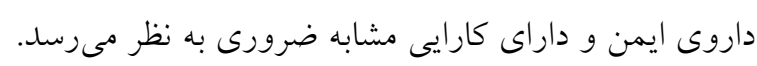

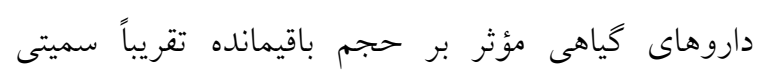

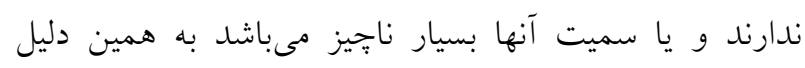

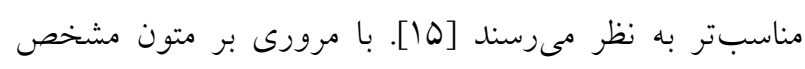

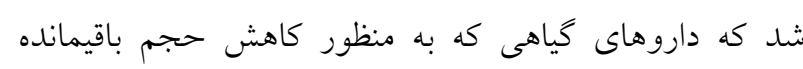

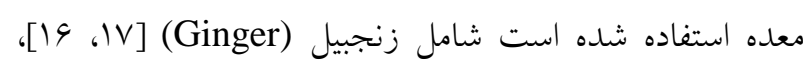

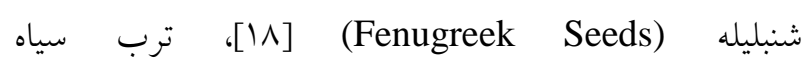

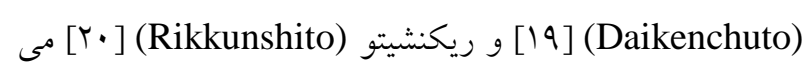
باشد. نتايج مطالعه نشان داد كه زنجبيل در مقايسه بالنيت

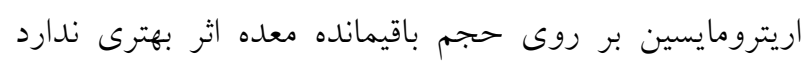

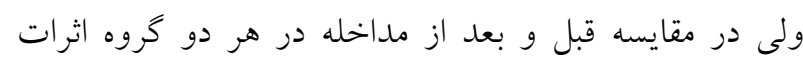

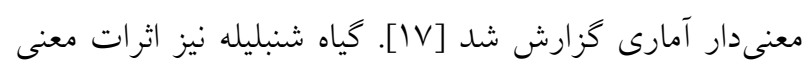

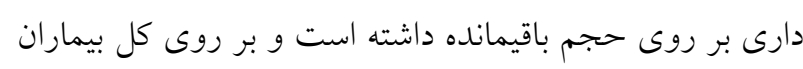

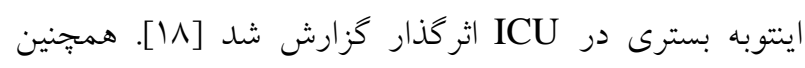

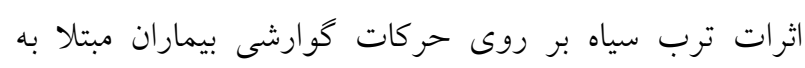

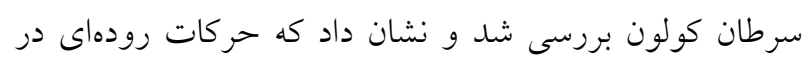

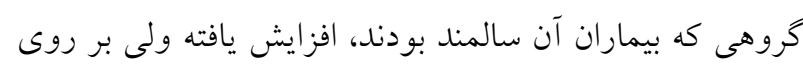

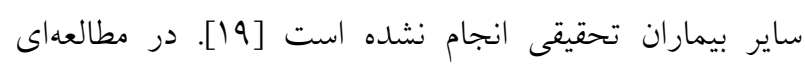
ديخر ريكنشيتو بر روى سرعت تخليه معده بيماران شديداً

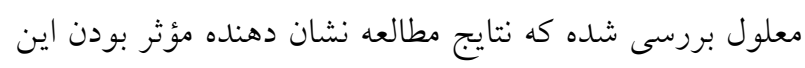

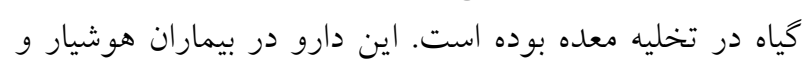

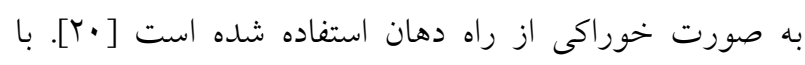

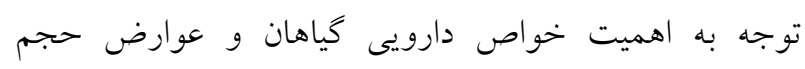

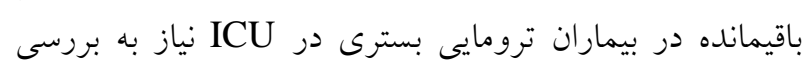

$$
\text { هاى بيشترى وجود دارد. }
$$

زيره سبز با نام علمى كومين سيمينوم

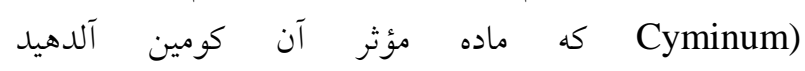
(Cuminaldehyde) مىباشد در كتب دارويى (Carvone)
يكى از مشكلات عمده در بيماران تحت تهويه مكانيكى در بخش مراقبتهاى ويزه كه از طريق لوله بينى - معدهاى تغذيه

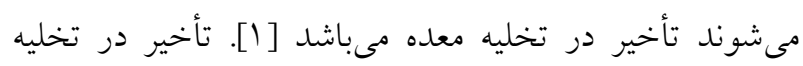

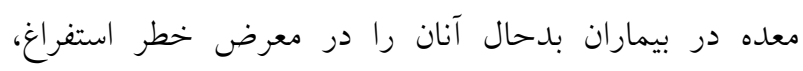

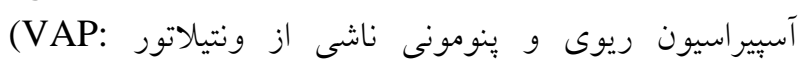
Ventilator Associated Pneomonia) كاهش سرعت تخليه و عدم تحمل تغذيه سبب احساس يرى،

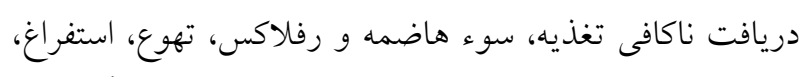

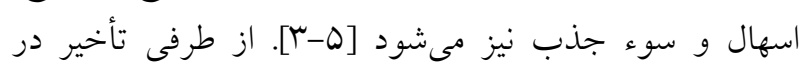

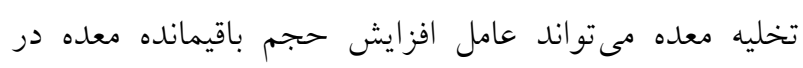

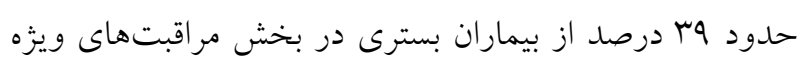

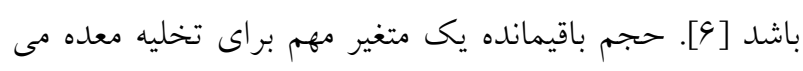

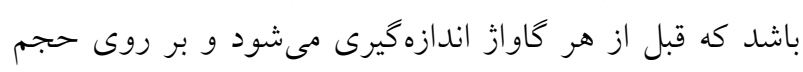

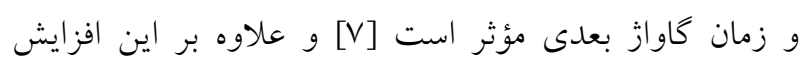

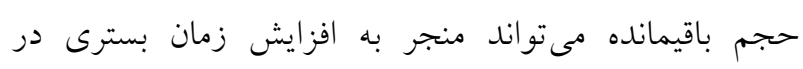

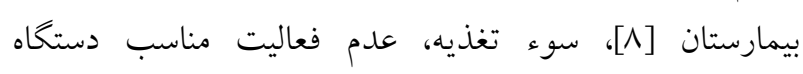

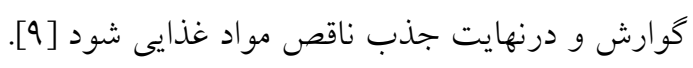

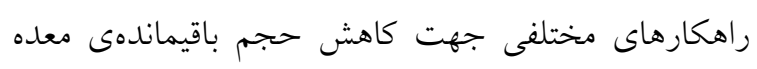

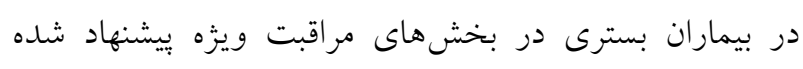

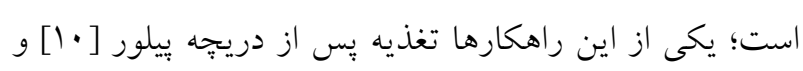
ديخرى استفاده از داروهاى بروكينتيك (Prokinetic Agent) ،(Metoclopramide)

$$
\text { متو كلوير اميد }
$$
اريترومايسين (Domperidone)

$$
\text { دوميريدون (مثل }
$$
(Erithromycin)

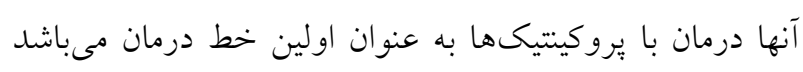

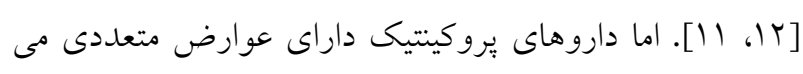

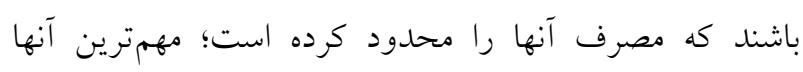
شامل: عوارض قلبى، هموديناميكى، عصبى و كوارشى مىباشد.

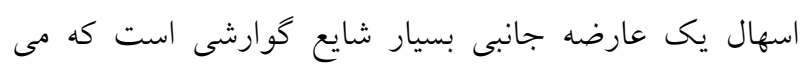

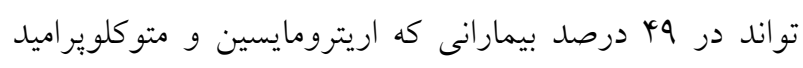

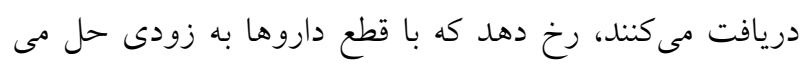

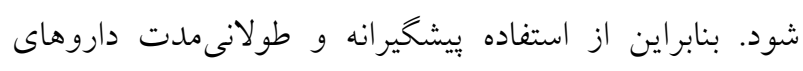

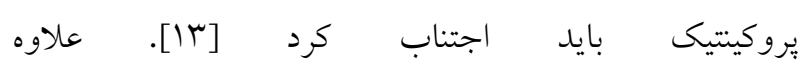




\section{مواد و روشها - - ماد}

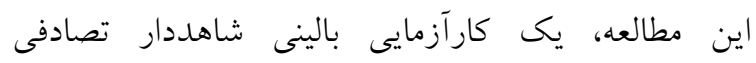

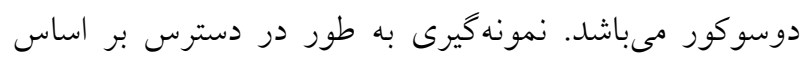

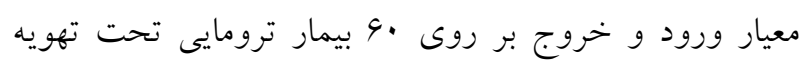

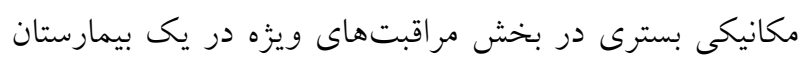
آموزشى شهرسارى انجام شد.

\section{معيارهاى ورود و خروج}

بيماران بسترى ترومايى داراى سوند معده و تحت ونتيلاتور،

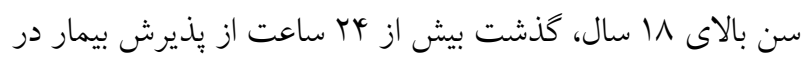

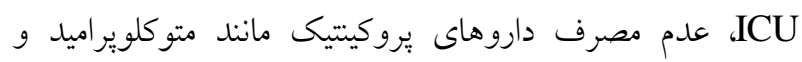

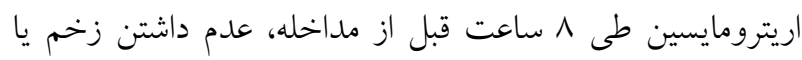

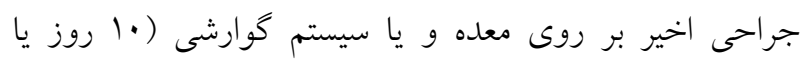

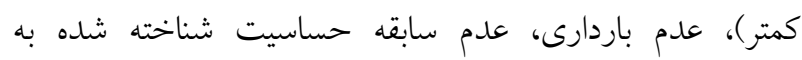

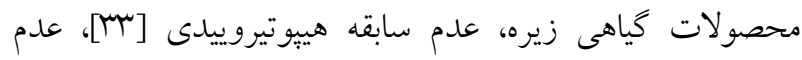

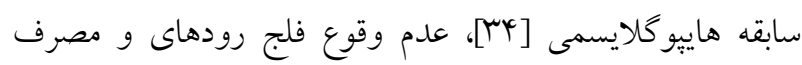

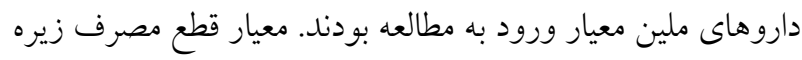

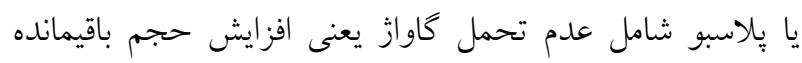

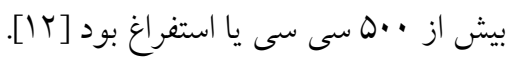
جس از انتخاب نمونهها رضايتنامه كتبى از قيم قانونى آنان

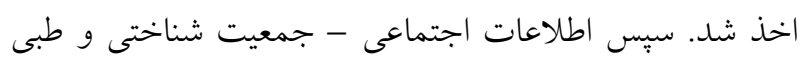
بيماران و حجم باقيمانده معده ثبت و توضيح در مورد اهداف آنساف

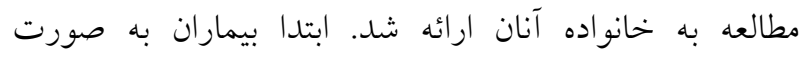

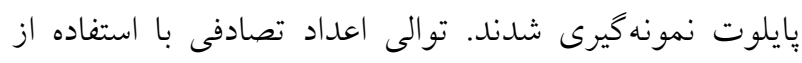

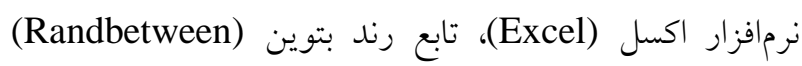

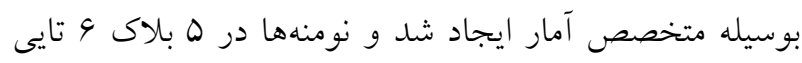

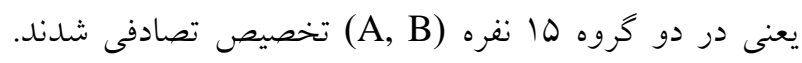

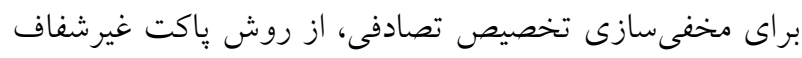

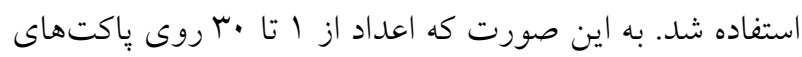

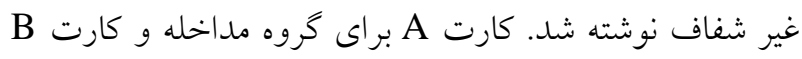

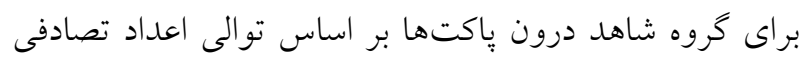

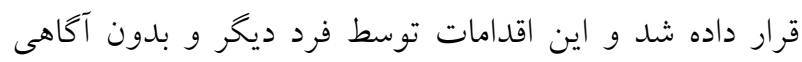

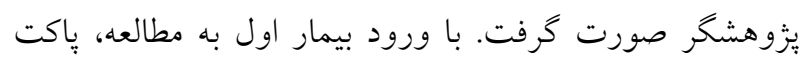

بسيارى از كشورها به رسميت شناخته شده است [ [Y]]. زيره

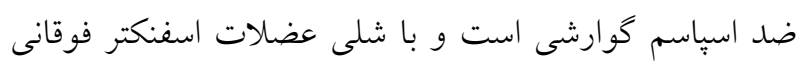

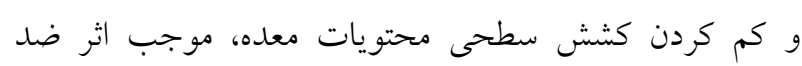

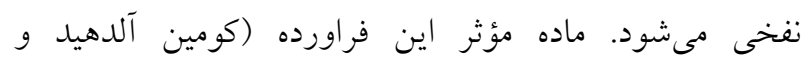

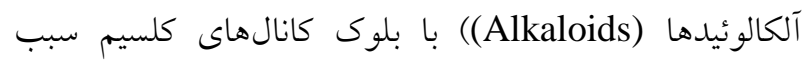

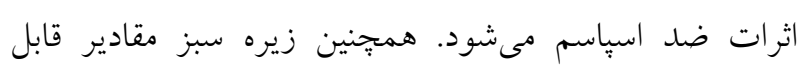

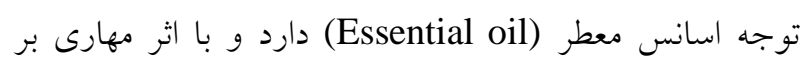

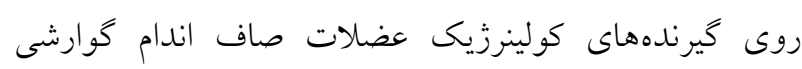

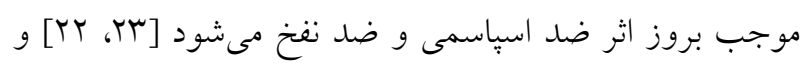

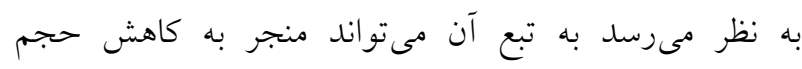

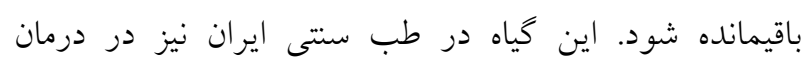

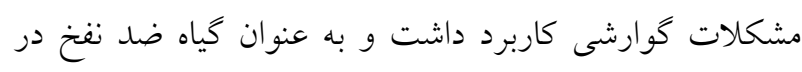

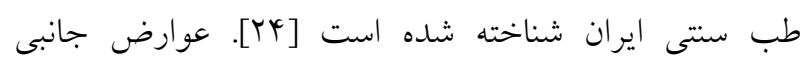

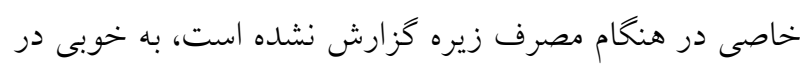

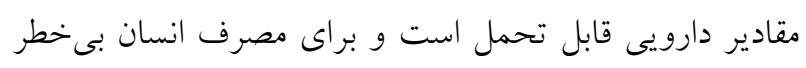

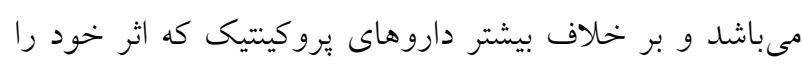

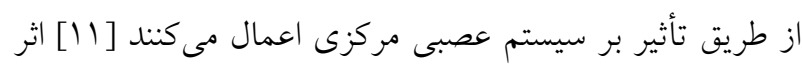

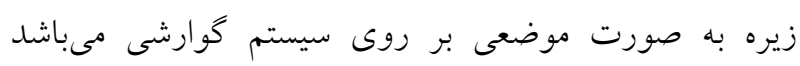

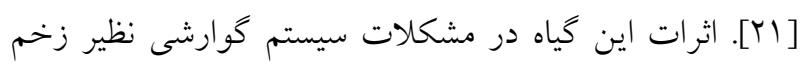

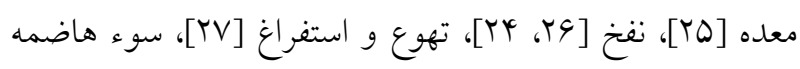

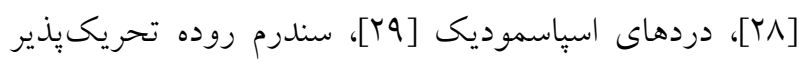

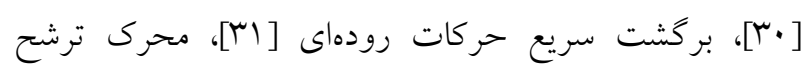

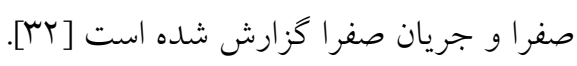

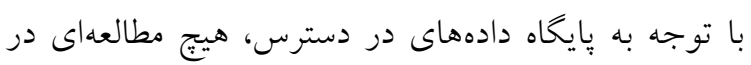

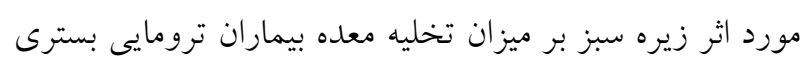

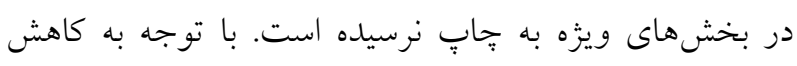

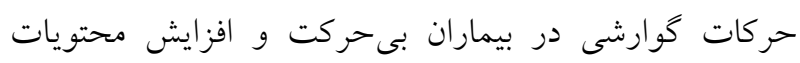

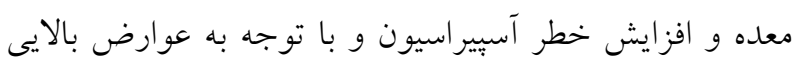

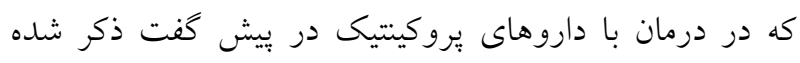

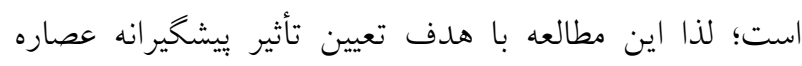

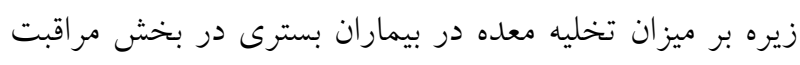

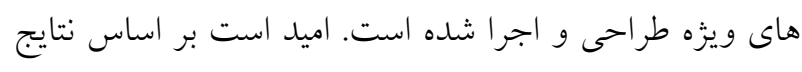

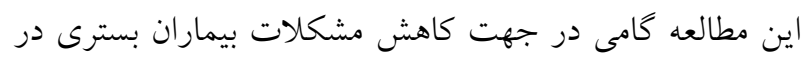

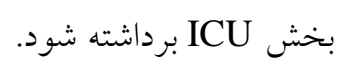


زده شد. حمايت تغذيهاى به صورت

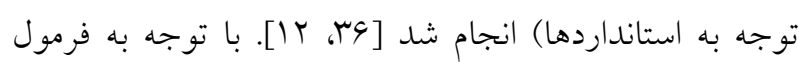

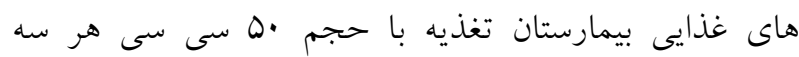

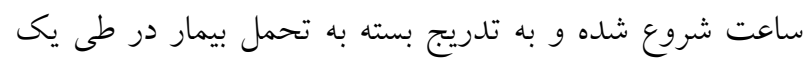

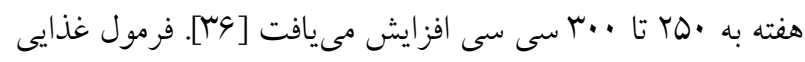

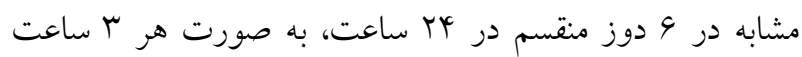

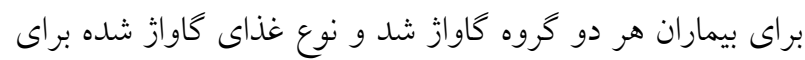

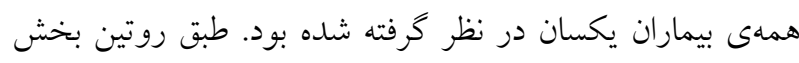

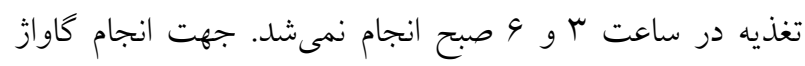

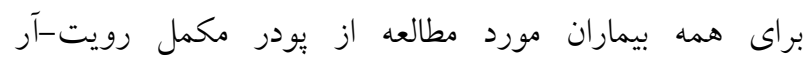
و سوبٍ بيمارستان (جهت يكسانسازى) استفاده شد.

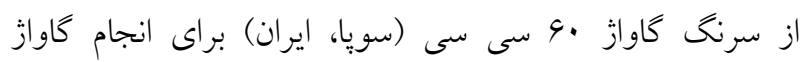

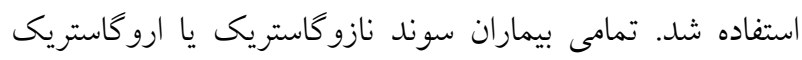

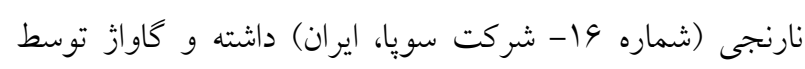

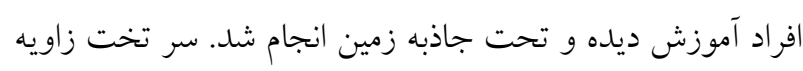

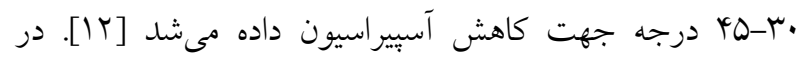

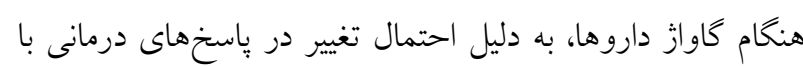

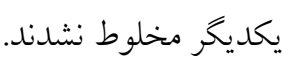

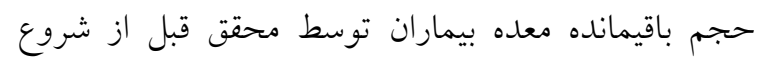

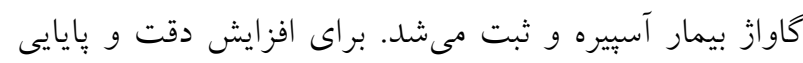

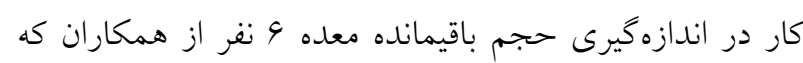

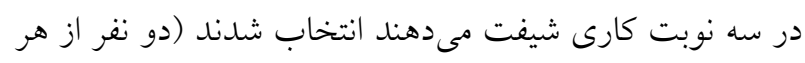

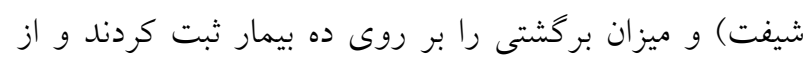

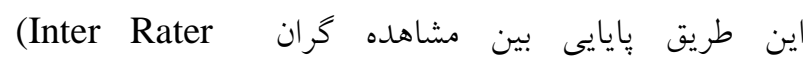
با آزمون آمارى ضريب همبستخى بين كروهى (Reliability) بررسى شد يد (ICC (Intraclass Correlation Coefficient))

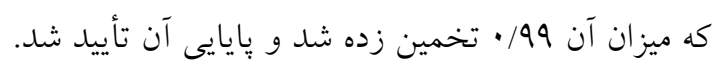

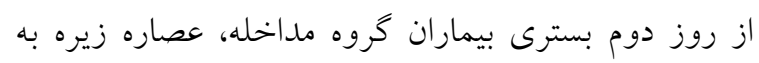
صورت زيره سبز (محصول شركت باريج اسانس، ايران) با دوز

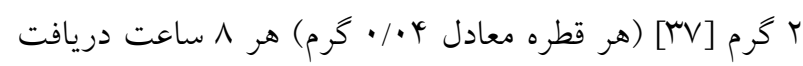

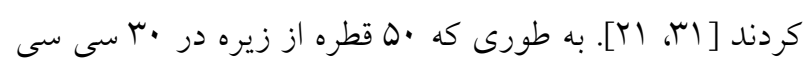

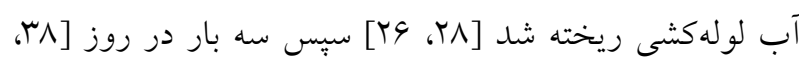

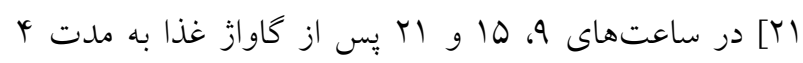

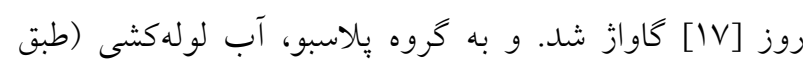

مربوط به شماره ا باز شد و گروه بيمار مشخص شد و بدين

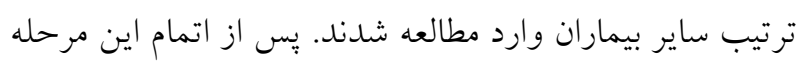

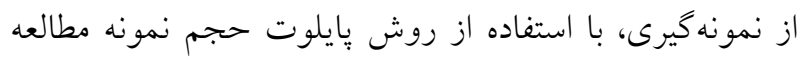

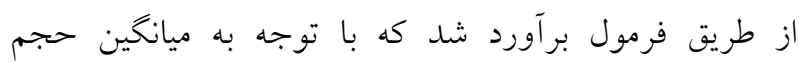

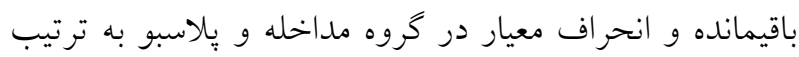

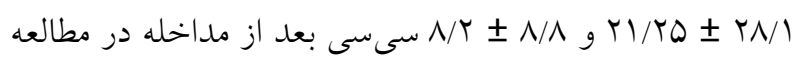

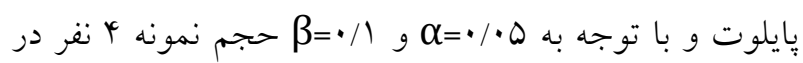
هر كروه برآورد شد.

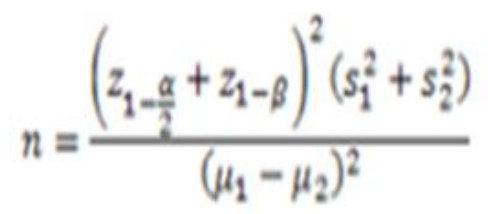

$$
n 1=n 2=\frac{(1.96+1.28)^{2}\left(8.2^{2}+21.25^{2}\right)}{(8.8-28.1)^{2}}=15
$$

جهت افزايش توان و دقت مطالعه و از طرفى با توجه به

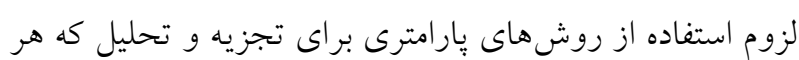

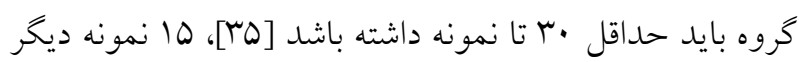

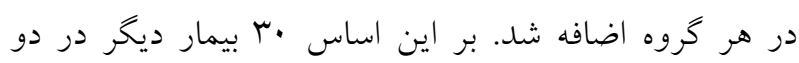

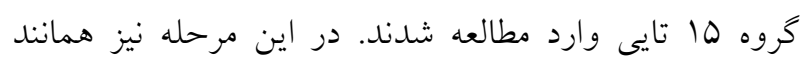

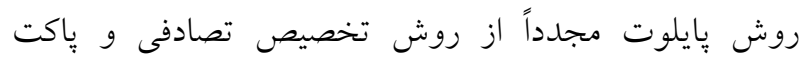

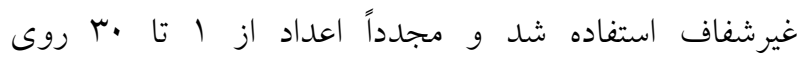
ياكتهاى غيرشفاف نوشته شد و بدين ترتيب نمونه كيرى انجام

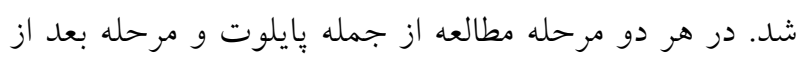

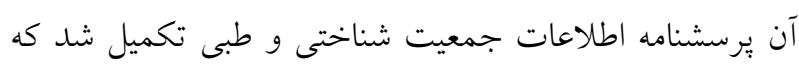

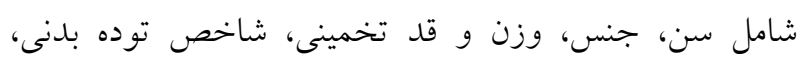

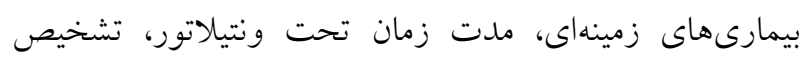

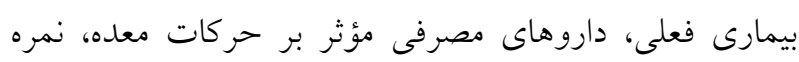
GCS

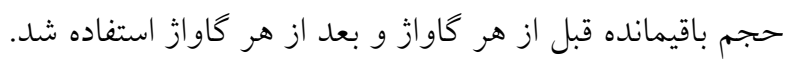

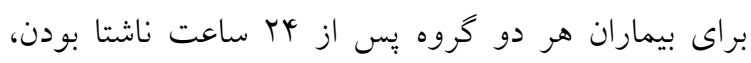

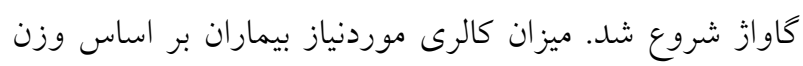

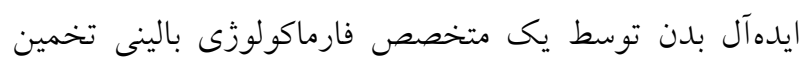




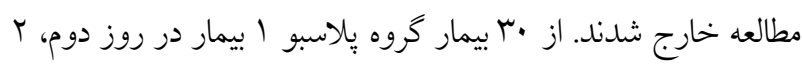

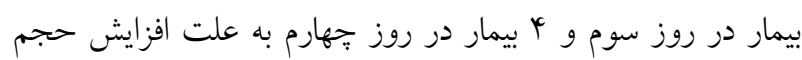

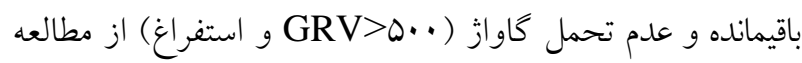

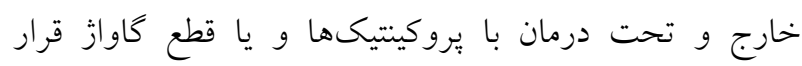

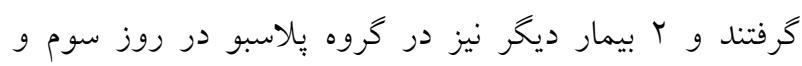

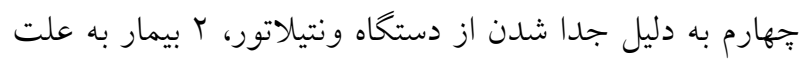

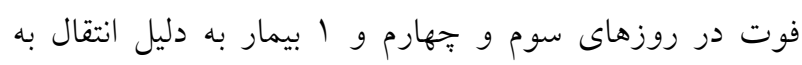

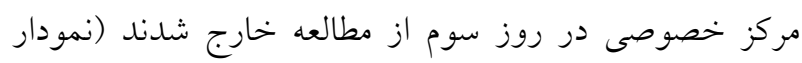

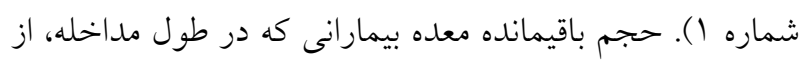

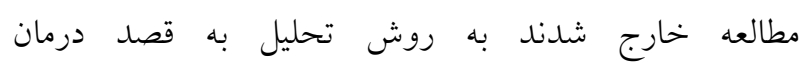

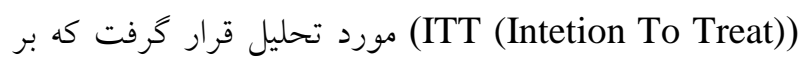
اساس آن براى برآورد دادههاى گم شده با استفاده از الخوريتم (EM (Expatiated Maximization))

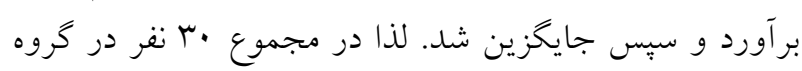

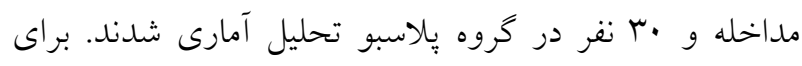

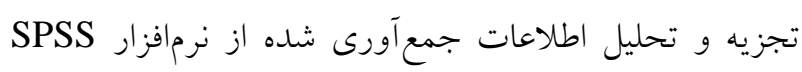

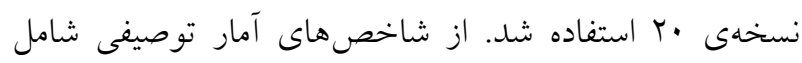

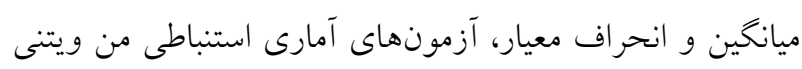

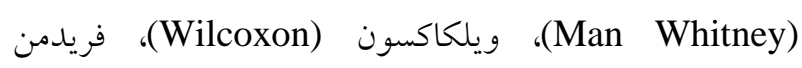
و معادله تخمين تعميميافته (جى -اى-اى) (Friedman) (Generalized Estimation Equation) نبودن دادهها استفاده شد و جهت مقايسه متغيرهاى كيفى از

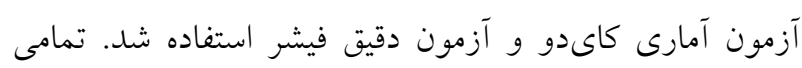
آزمونها در سطح معنىدارى هـ • • انجام شد.
روتين بخش كه بعد از كاواز غذا، آب داده مىشود) به صورت

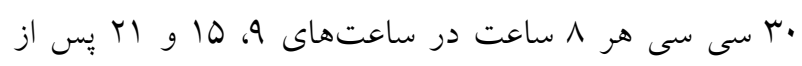

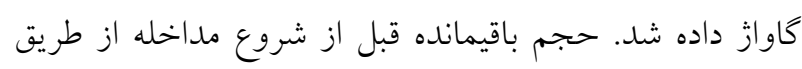

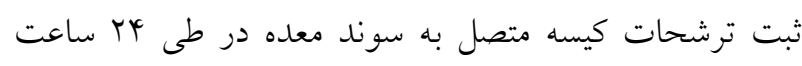

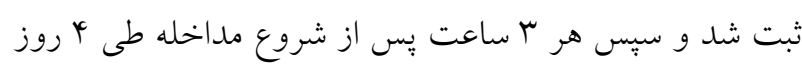

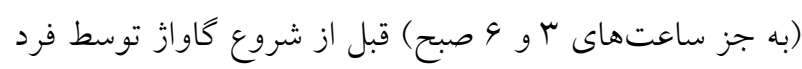

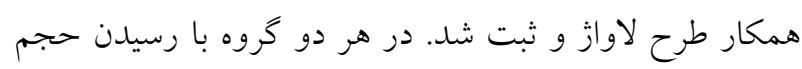

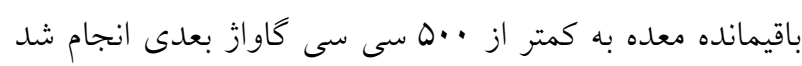

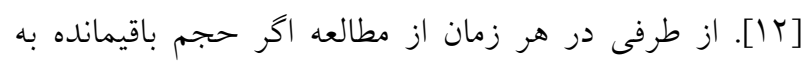

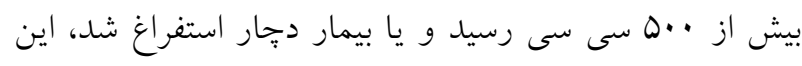

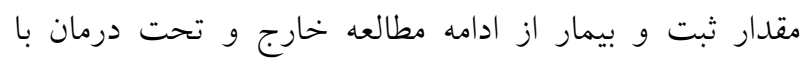

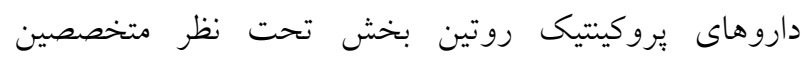

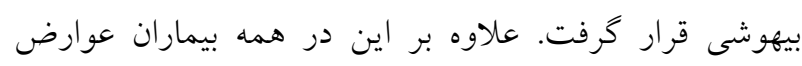

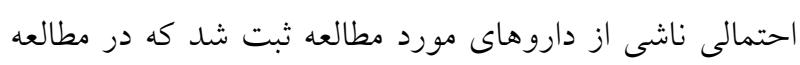
حاضر عارضهاى رويت نشد. جهت دو سوكور شدن مطالعه، بيمار و ارزياب از نوع داروى دريافتى اطلاعى نداشتند.

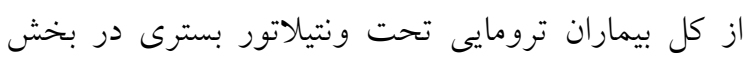

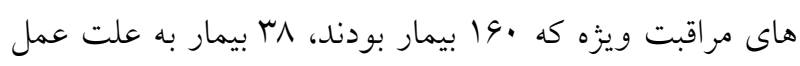

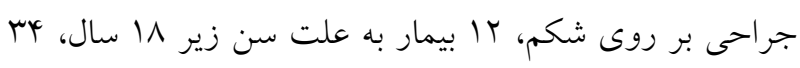

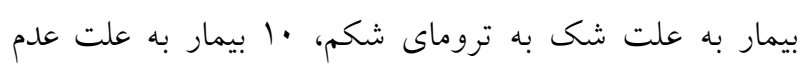

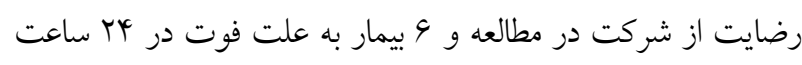

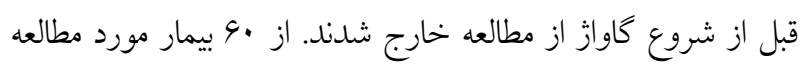

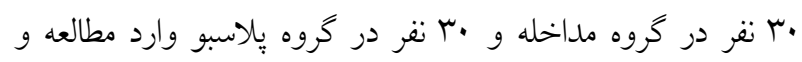

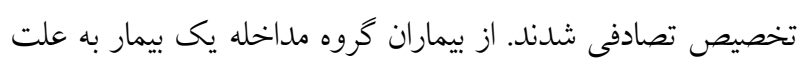

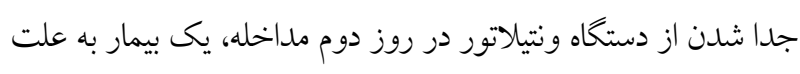
تشخيص سرطان معده در روز سوم مطالعه و يك بيمار به دليل در روز دوم مداخله از (GIB (Gastro Intestinal Bleeding)) 


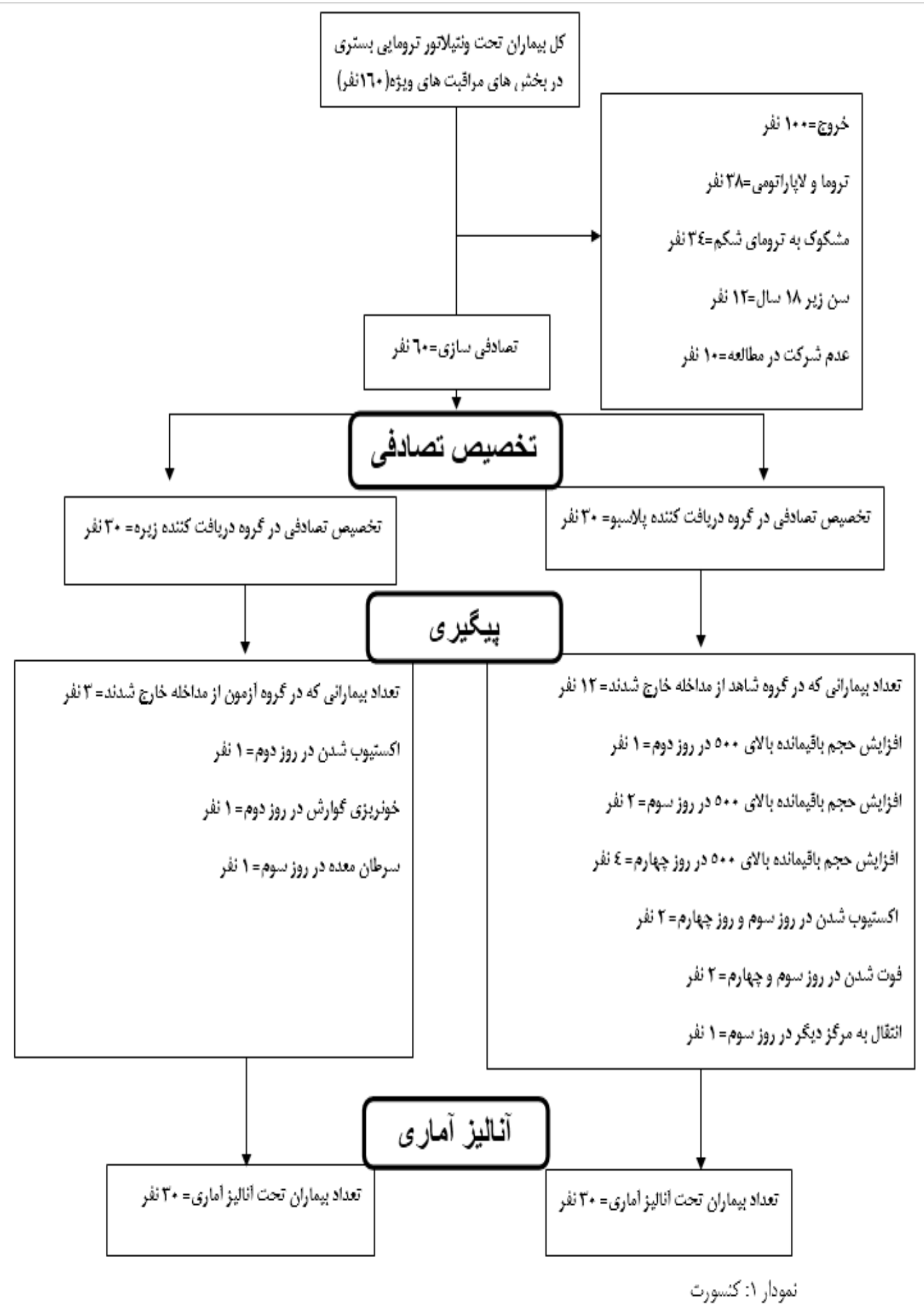


مغزى بوده است. در تروماى جّند ارگان (MT) تروماى اندامها با تروماى سر يا بدون تروماى سر همراه بود. بيمارى هاى زمينه دو گروه از نظر متغيرهاى سن، شاخص توده بدنى، كالرى،

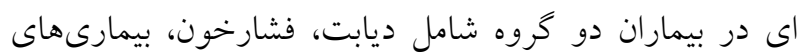

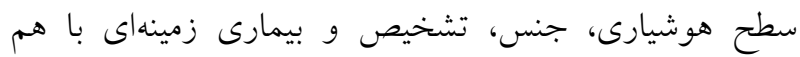

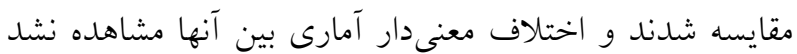

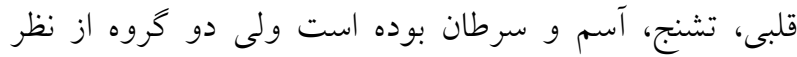
بيمارى زمينهاى نيز اختلاف معنى دار آمارى نداشتند (

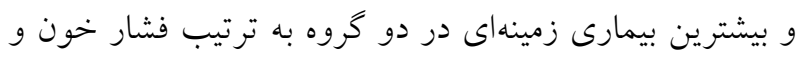

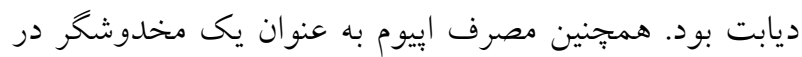

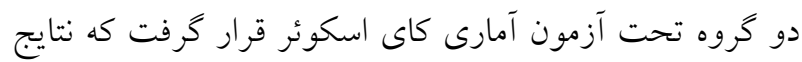
نشان داد كه اين تعداد در گروه مداخله بيشتر بوده است

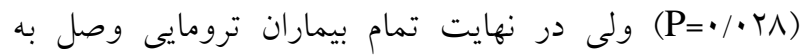
ونتيلاتور، جهت كاهش مقاومت با دستخاه ونتيلاتور به صورت روتين تحت انفوزيون سداتيوها و مواد مخدر (مرفين و ونان

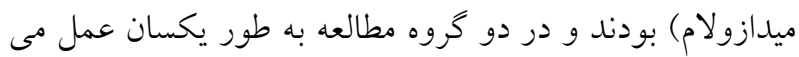
شد (جدول شماره (1). ولى در مقايسه دو گروه از نظر مصرف مواد مخدر اين اختلاف معنى ار بود (جدول شماره ()). تشخيص بر اساس تروماى ترافيكى و غيرترافيكى بوده است و

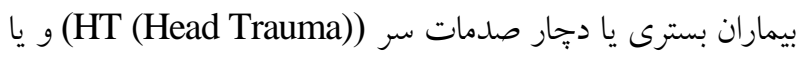
صدمات متعدد در جند اركان بودند (MT (Multiple Trauma). صدمات سر در دو گروه به صورت خونريزى تحت عنكبوتيه (SAH (Sub Arachnoid Hemorrhage)) دورا (SDH (Sub Dural Hematoma)، خونريزى اطراف دورا (EDH (Epidural Hematoma) (2) خونريزى بافت مغز (ICH (Intra Cerebral Hemorrhage)) بطن مغز (IVH (Intra Ventricular Hemorrhage)) و ادم جدول شماره ا- مقايسه ميانكين و فراوانى دو گروه مداخله و بلاسبو از نظر متغيرهاى دموكرافيك و طبى در بيماران ترومايى تحت ونتيلاتور بسترى در

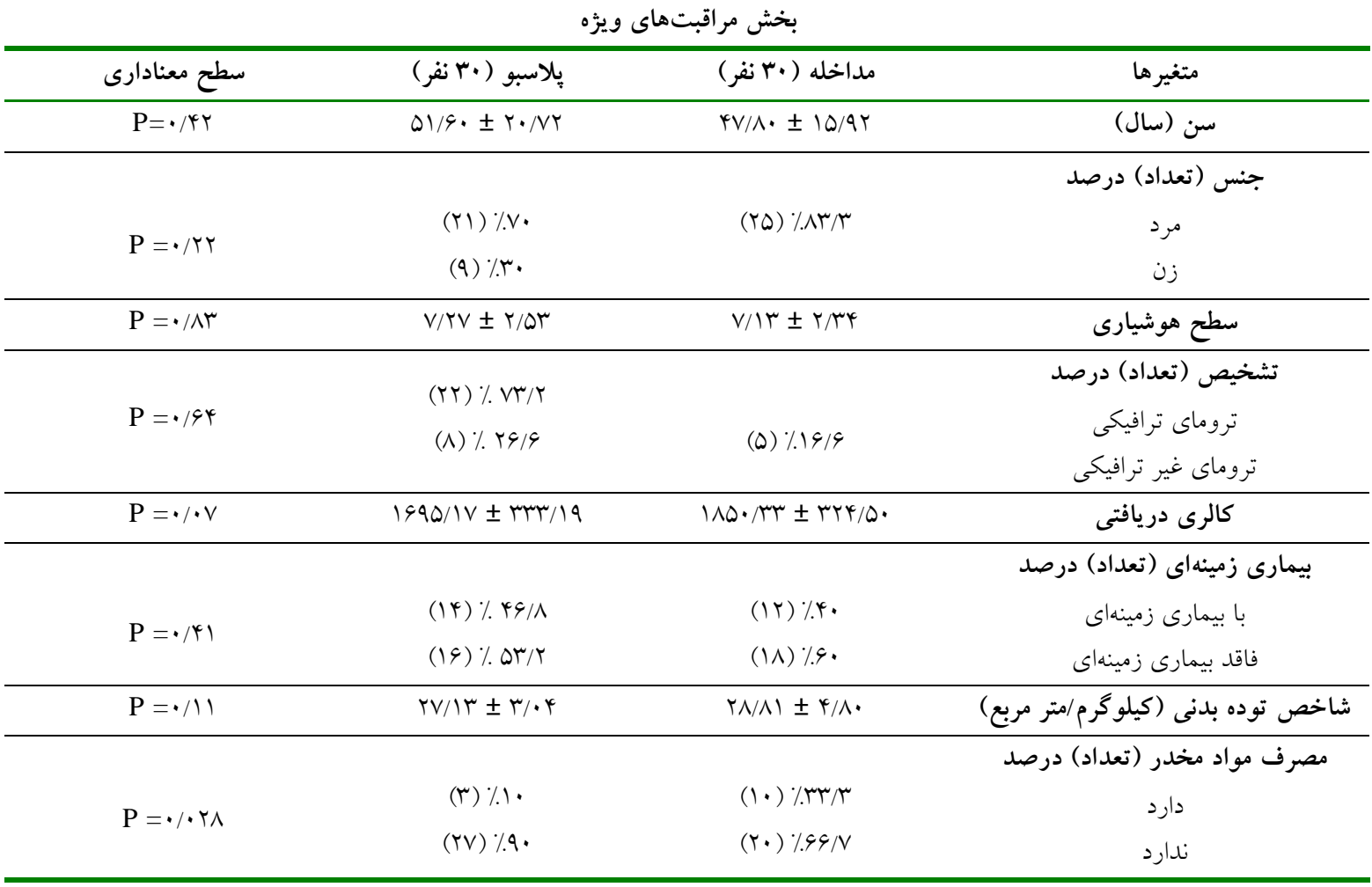


تأثير بيشخيرانه عصاره زيره ...

ميزان حجم باقيماندهى معده در دو كروه در روز اول اختلاف

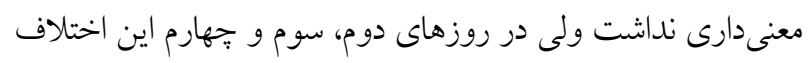

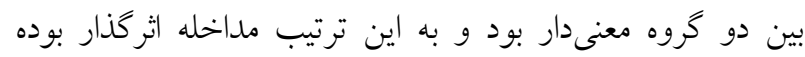

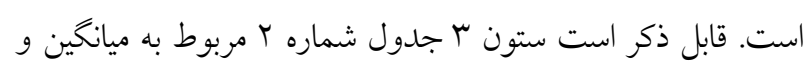

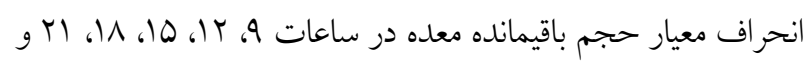

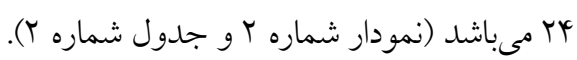

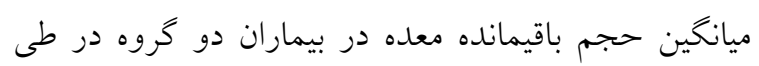

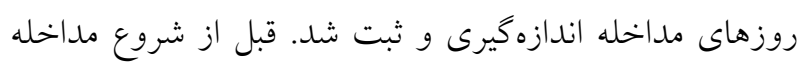

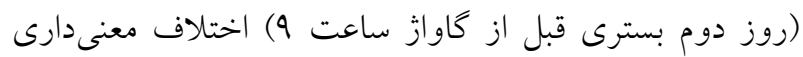

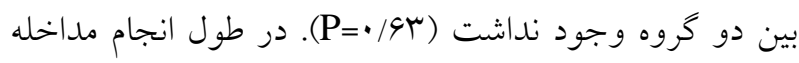

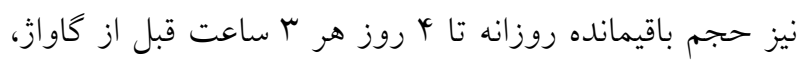

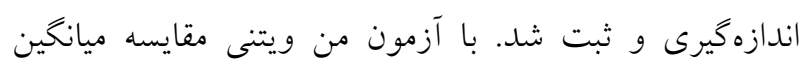

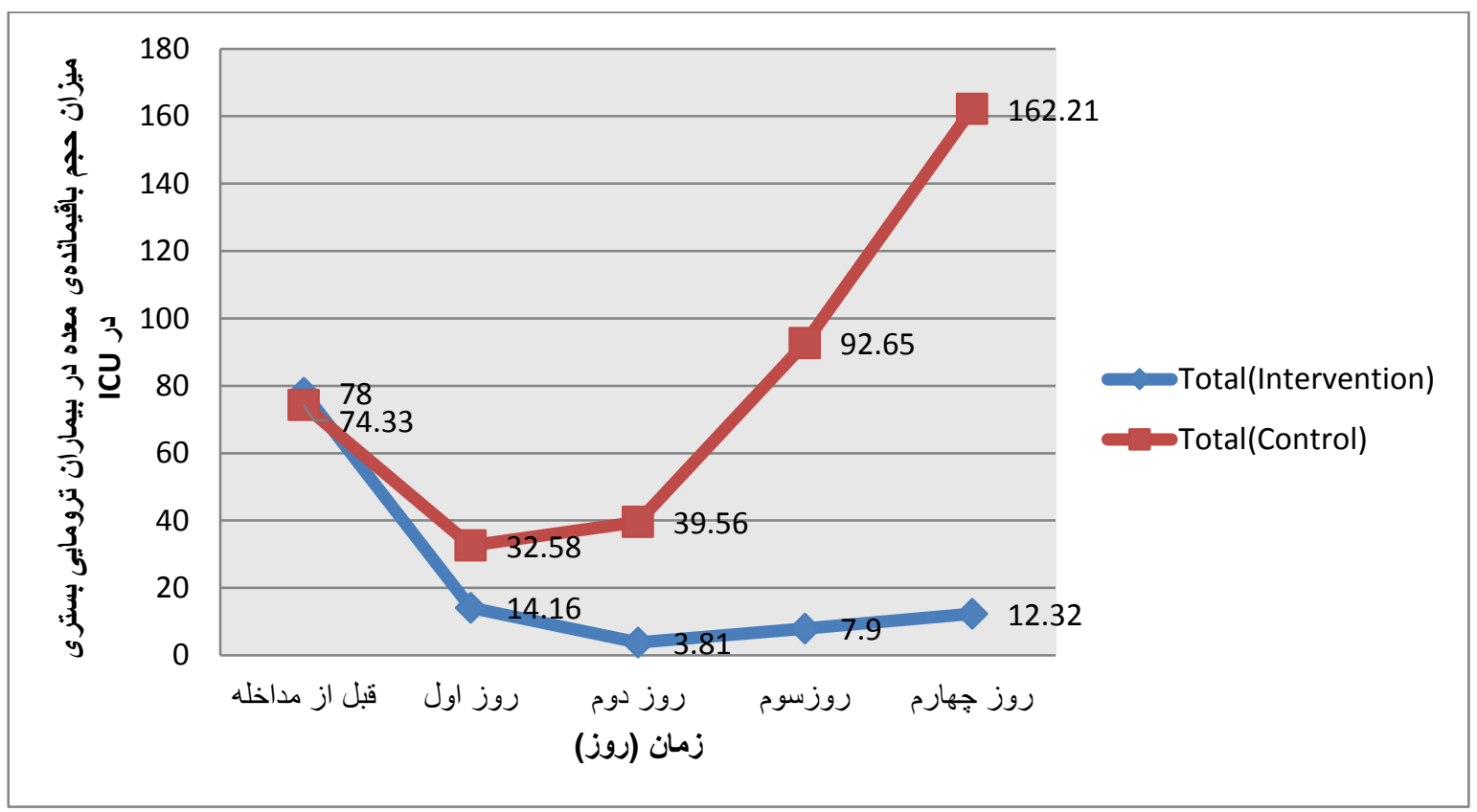

نمودار شماره Y - مقايسه ميانكين حجم باقيمانده در دو گروه مداخله و بِلاسبو در قبل از مداخله و طى † روز بعد از شروع مداخله

جدول شماره Y- مقايسه ميانگين ميزان حجم باقيماندهى معده در بيماران ترومايى بسترى در ICU قبل از شروع با روز اول، دوم، سوم و جهارم مداخله

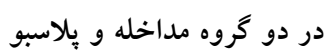

\begin{tabular}{|c|c|c|c|c|}
\hline سازمون معنى دارى با & ميانگين رتبه & & كروه & حجم باقيمانده معده \\
\hline \multirow{2}{*}{.$/ 94$} & $\Gamma_{1 / \Delta \omega}$ & $V \wedge \pm \wedge \& / T V$ & مداخله & \multirow{2}{*}{ قبل از شروع مداخله } \\
\hline & $r q / 4 Q$ & $V 4 / T \pm 11 \% / 9 V$ & ليلاسبو & \\
\hline \multirow{2}{*}{. } & $T V / 10$ & $1 \% / 19 \pm 10 / \mu \Lambda$ & مداخله & \multirow{2}{*}{ روز اول } \\
\hline & $\Gamma / \Lambda \Delta$ & $r T / Q \Lambda \pm Y Q / / Q$ & ي يلاسبو & \\
\hline \multirow{2}{*}{$\cdot / . .1$} & TI/AY & $r / \Lambda| \pm| \psi / \Gamma \mid$ & مداخله & \multirow[b]{2}{*}{ روز دوم } \\
\hline & $r q / \Delta \wedge$ & $r Q / \Delta Q \pm \Delta Q / 19$ & يلاسبو & \\
\hline \multirow{2}{*}{$\cdot / . .1$} & IN/9Y & $V / q \cdot \pm T V / T Q$ & مداخله & \multirow[b]{2}{*}{ روز سوم } \\
\hline & $r Y / \cdot \Lambda$ & $9 r / 90 \pm 1 \cdot r / \wedge 9$ & يلاسبو & \\
\hline \multirow{2}{*}{.$\cdots 1$} & $19 / 1$. & IT/RT \pm rG/NA & مداخله & \multirow{2}{*}{ روز جهارم } \\
\hline & $\varphi 1 / 9$. & $|G T / T| \pm \mid 19 / N T$ & "ِلاسبو & \\
\hline
\end{tabular}


كه در گروه يلاسبو، ميانخين حجم باقيمانده معلده با كذشت

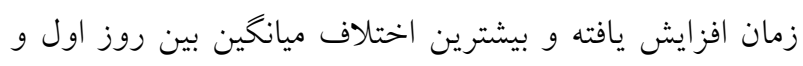

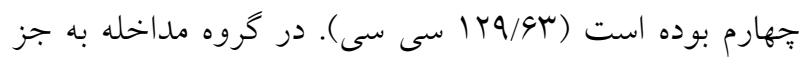

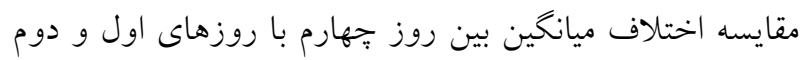

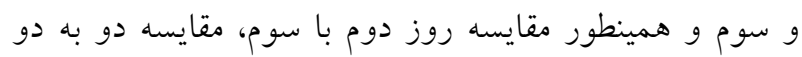

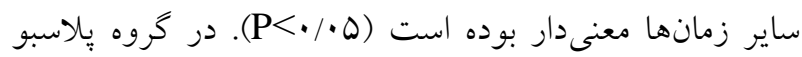

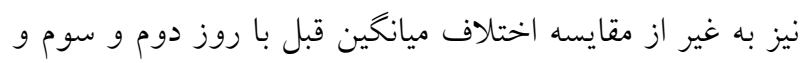

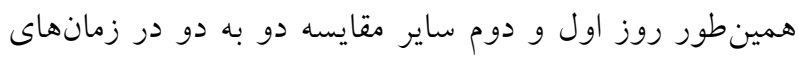

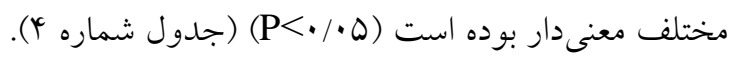

جون دادهها توزيع نرمال نداشتند براى مقايسه اثر مداخله

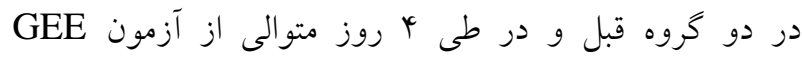

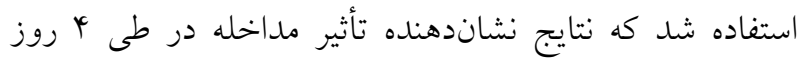
مداخله و در طى زمان بوده است (جدول شماره r).

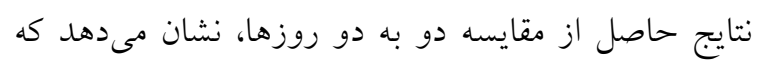

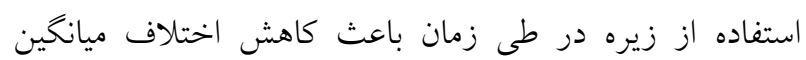

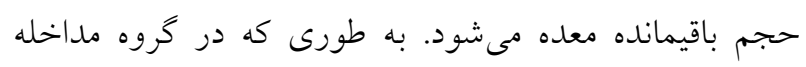

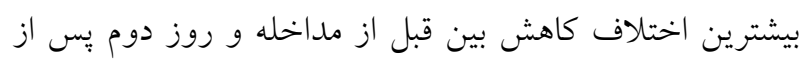

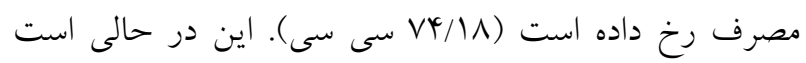

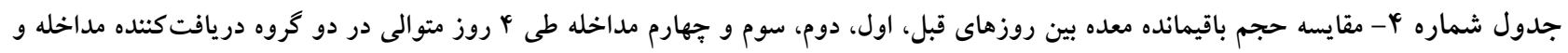

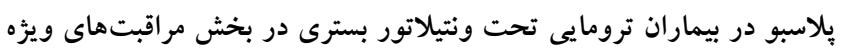

\begin{tabular}{|c|c|c|c|c|}
\hline سطح معنى دارى با آزمون ويلكاكسون & اختلاف ميانخين & ساير روزها & 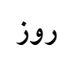 & 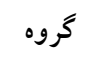 \\
\hline$\cdot / \cdot \cdot 1$ & $-9 \mu / \Lambda \mu$ & اول & \multirow{4}{*}{ قبل } & \multirow{10}{*}{ 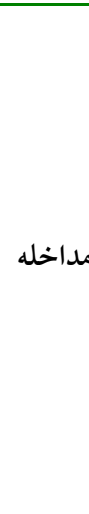 } \\
\hline$\cdot \cdot \cdot 1$ & $-V \Psi / \Lambda \Lambda$ & 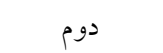 & & \\
\hline$\cdot / \cdot 1$ & $-v \cdot / \cdot q$ & 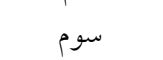 & & \\
\hline$\cdot / \cdot 1$ & $-90 / 9 \mathrm{~V}$ & 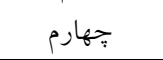 & & \\
\hline$\because \cdot \cdot r$ & $-1 \cdot \pi \Delta$ & دوم & \multirow{3}{*}{ اول } & \\
\hline.$\cdot \cdot 9$ & $-9 / 49$ & 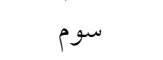 & & \\
\hline$\cdot / \cdot \Lambda$ & $-1 / \Lambda r$ & جهارم & & \\
\hline$\cdot / \cdot V \Delta$ & $4 / \bullet \wedge$ & 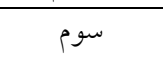 & \multirow{2}{*}{ دوم } & \\
\hline$\cdot 1 \cdot 19$ & N/Q1 & جهارم & & \\
\hline.$/ 1 \cdot r$ & Y/YT & ج جهارم & 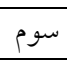 & \\
\hline.$/ \cdot 9$ & $-Y / N Q$ & اول اول او & \multirow{4}{*}{ قبل } & \multirow{10}{*}{ بلاسبو } \\
\hline$\cdot / T \cdot V$ & -MYNG & 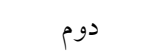 & & \\
\hline.$/ 101$ & $|N / \mu|$ & 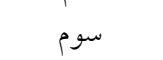 & & \\
\hline$\cdot / \cdot r$ & $\Lambda \mathrm{V} / \mathrm{\Lambda \Lambda}$ & 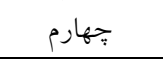 & & \\
\hline$\cdot / \Delta V$ & $9 / 91$ & دوم & \multirow{3}{*}{ اول } & \\
\hline.$\cdots 1$ & 9.1 .4 & 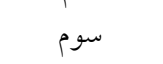 & & \\
\hline$\cdot / \cdot 1$ & $1 \% Q / 94$ & جهارم & & \\
\hline.$/ \cdot 1$ & $\Delta r / \cdot \wedge$ & سوم & \multirow[b]{2}{*}{ دوم } & \\
\hline$\% \cdot 1$ & $\mid r T / 90$ & 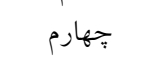 & & \\
\hline$\% \cdot \cdot 1$ & $99 / 09$ & جهارم & سوم & \\
\hline
\end{tabular}


مهارى بر روى كيرندهاى كولينرزيك عضلات صاف اندام

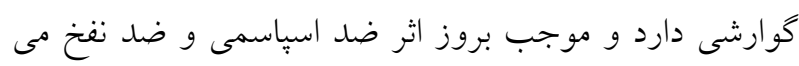

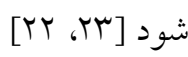

در مطالعه حاضر با توجه به توصيه كتب طب سنتى از زيره

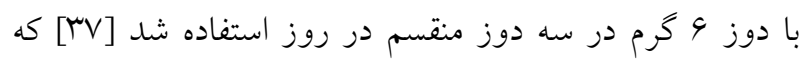

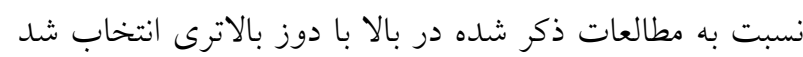

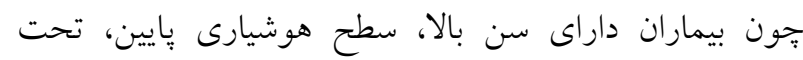

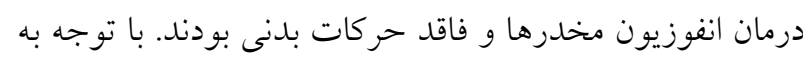

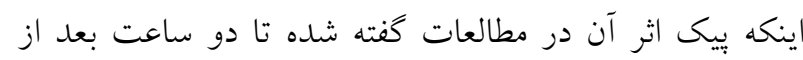

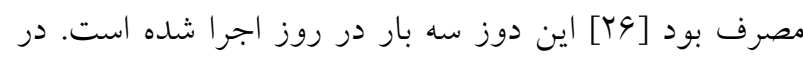

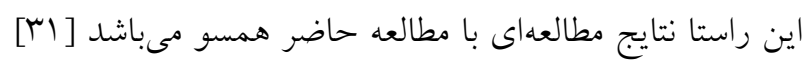

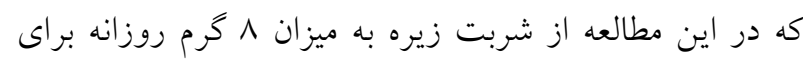

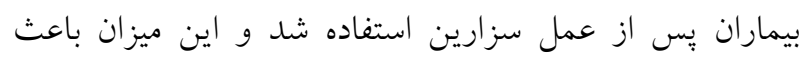

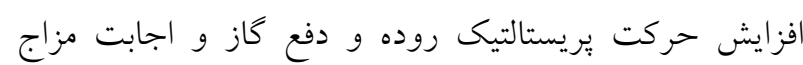

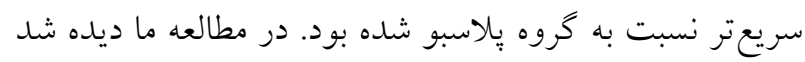

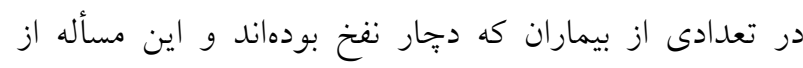

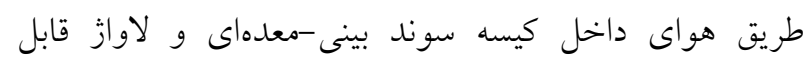

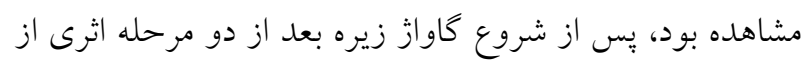

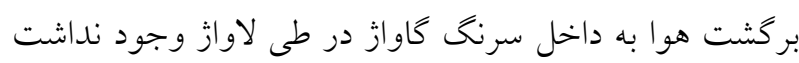

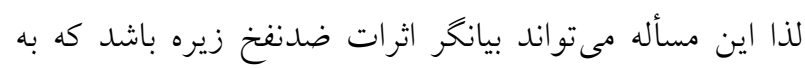
تبع آن منجر به افزايش سرعت تخليه مىشودا

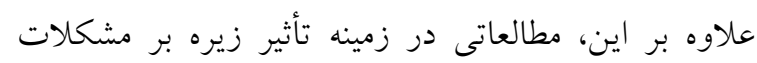

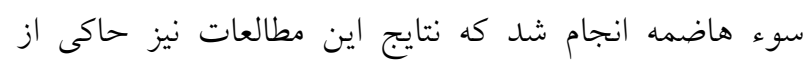

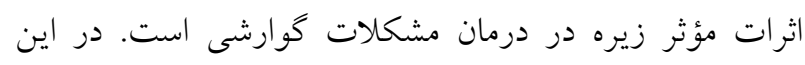
راستا مطالعهاى تحت عنوان درمان سوء هاضمه در درمان منات تركيب

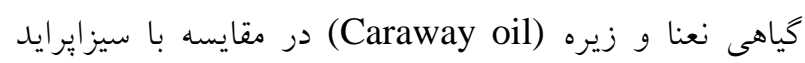

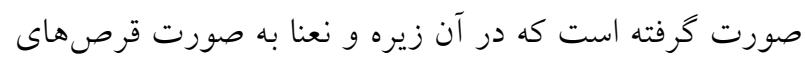

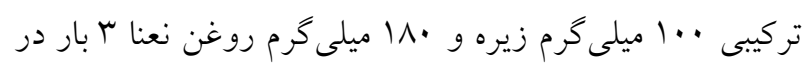

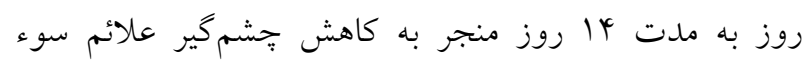

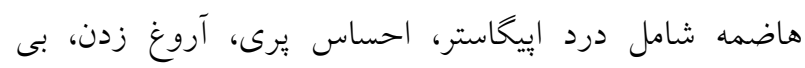

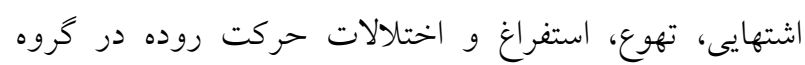

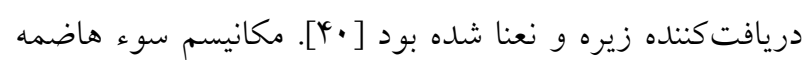

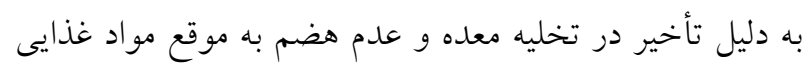
در معده مىباشد، به نظر مى رسد زيره با افزايش فعاليت آنزيم
نتايج اين مطالعه نشان داد كه عصاره زيره سبب كاهش

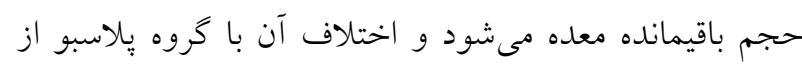

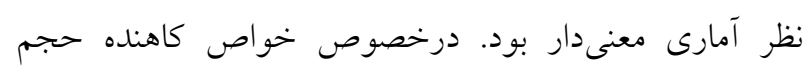

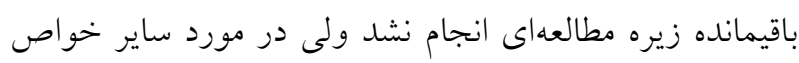

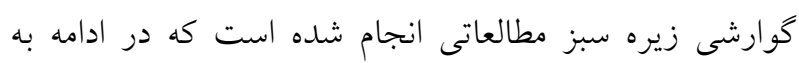

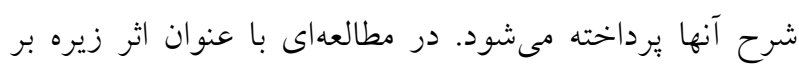

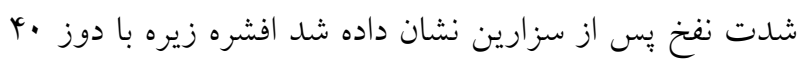

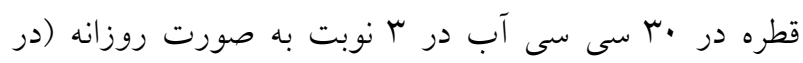

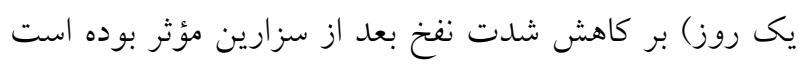

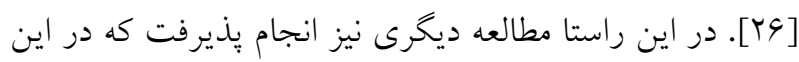
يزوهش نيز شدت نفخ در سه گروه دريافت كننده زيره، نعنا و

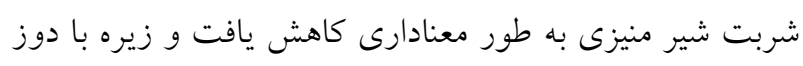

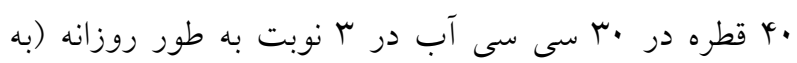

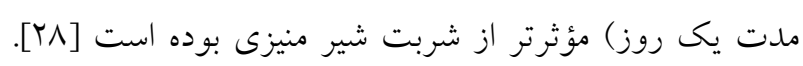

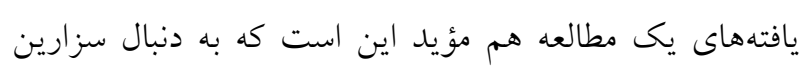

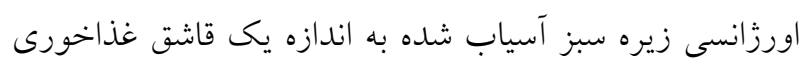

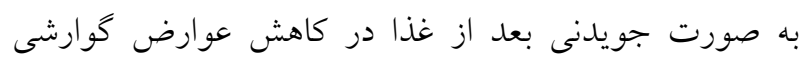
مانند نفخ شكم مؤثر است و حتى مؤثرتر از شير منيزى مى بعى إنى

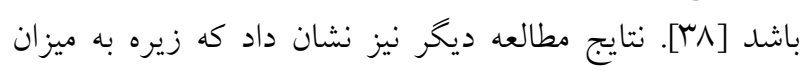

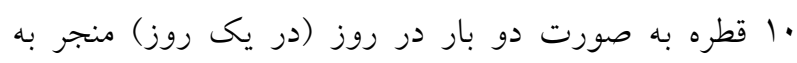

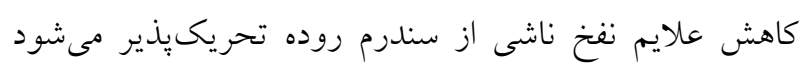

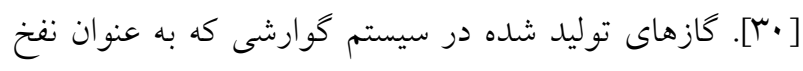

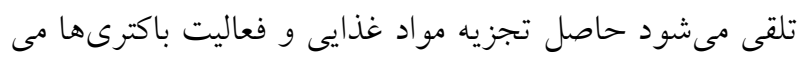

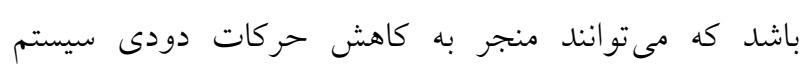

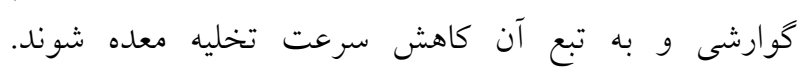

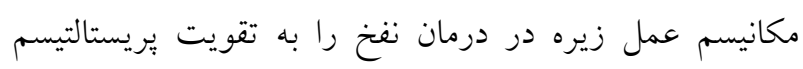

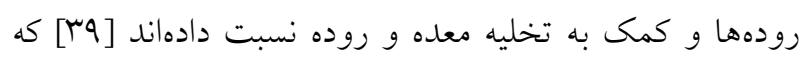

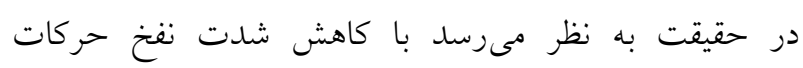

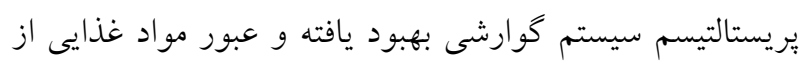

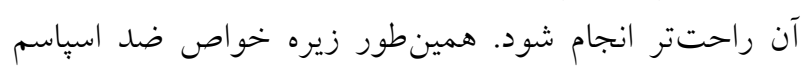

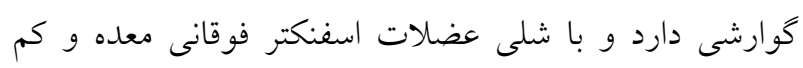

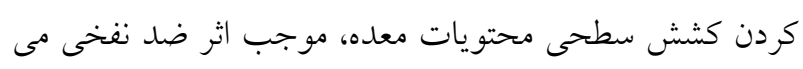

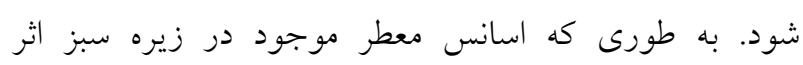


بيماران، به انجام تحقيقات بيشتر و انجام مداخله در روزهاى

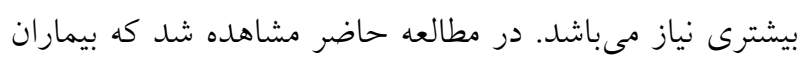

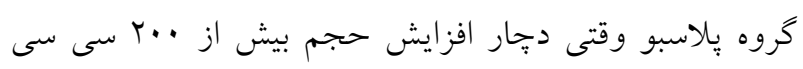

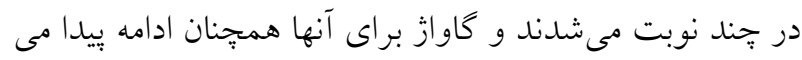

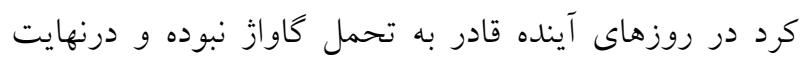

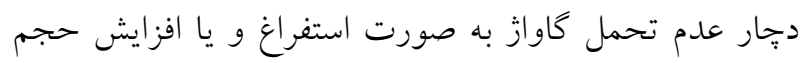

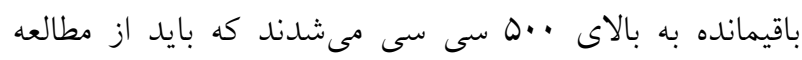

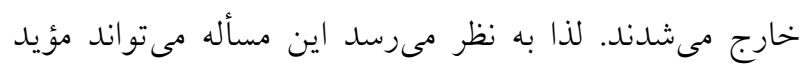

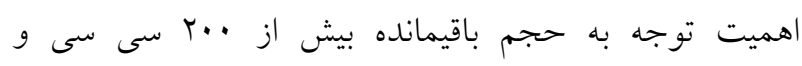

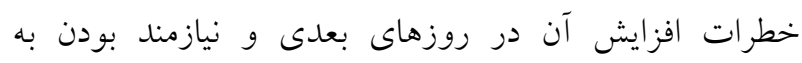

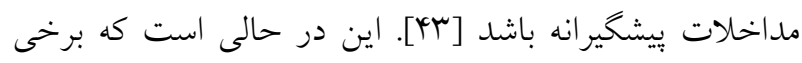

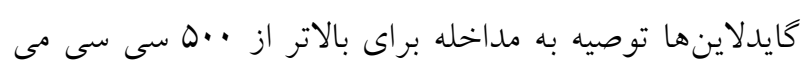

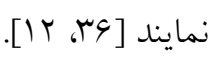

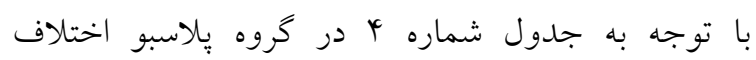

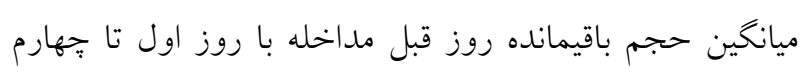

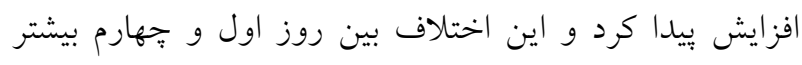

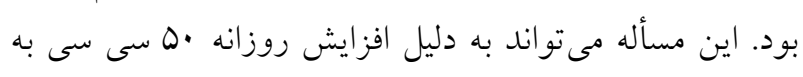

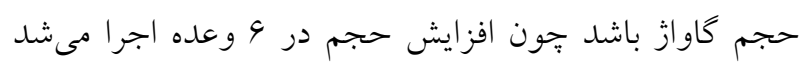

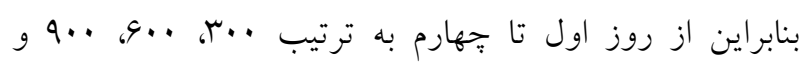

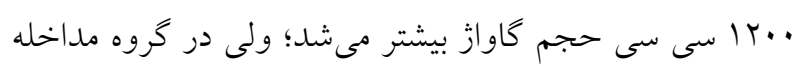

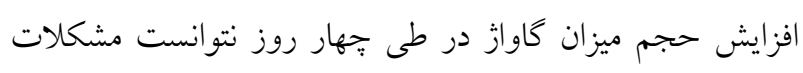

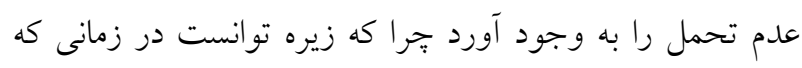

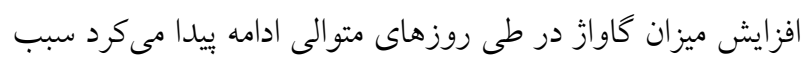

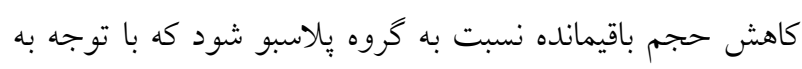

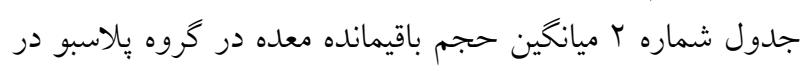

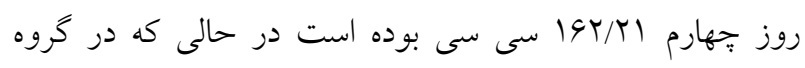

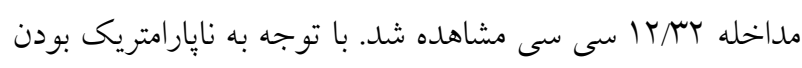

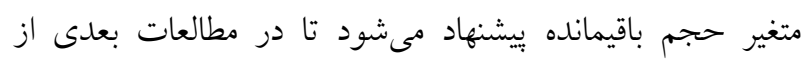

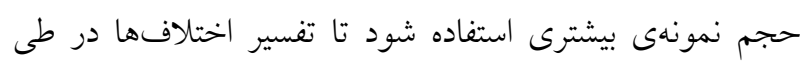

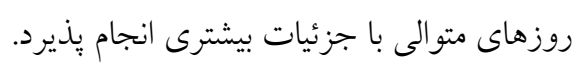

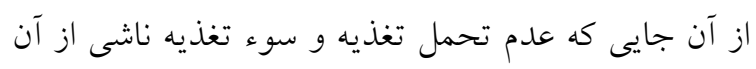

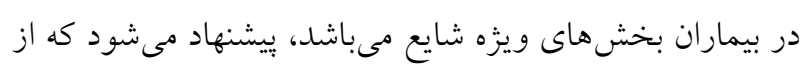

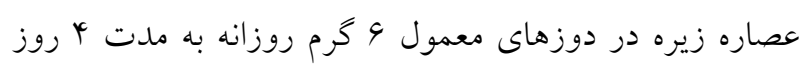

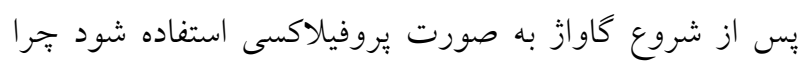

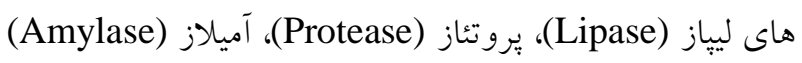

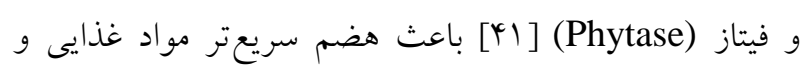

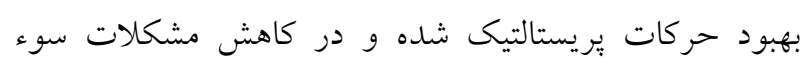
هاضمه مؤثر واقع مى شيود. در كتب طب سنتى نيز بيان شده استفاده از كياهان دارويى هوديى

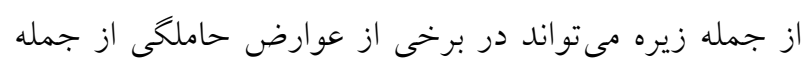

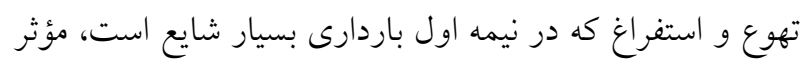

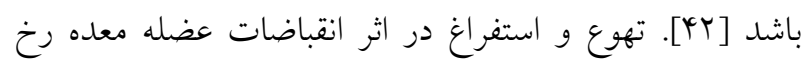

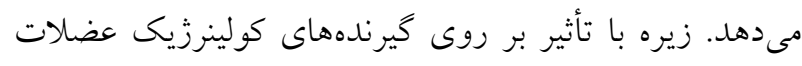

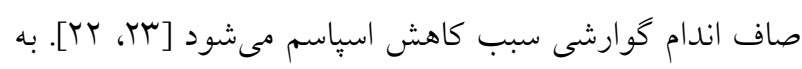
نظر مىرسد كه كاهش تهوع و استفراغ مى تواند منجر به كاهش آنش

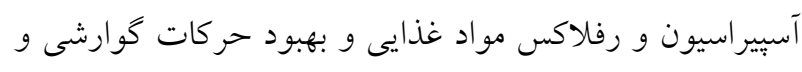

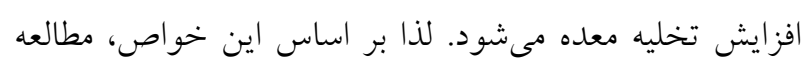
حاضر طراحى شد. مطالعه حاضر نشان داد كه عصاره زيره به به صورت

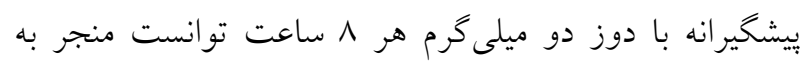

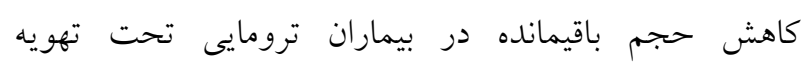

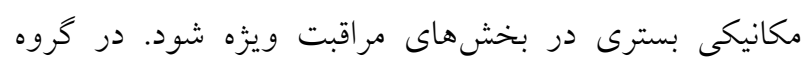

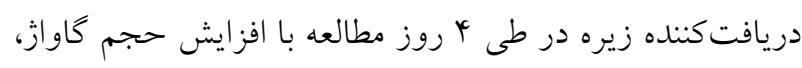

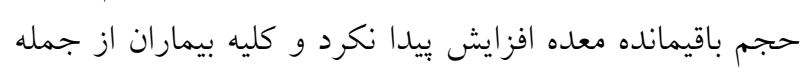

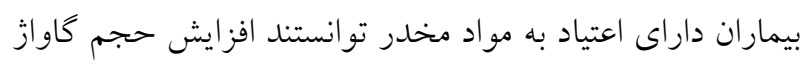

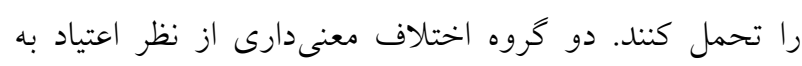

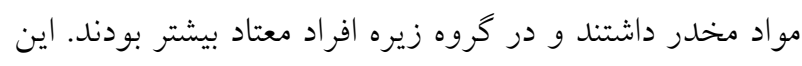

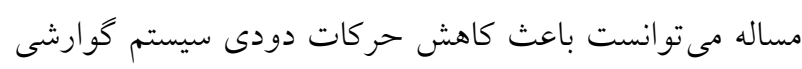

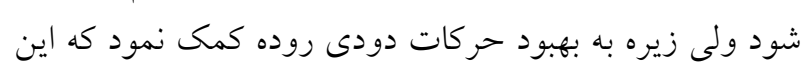

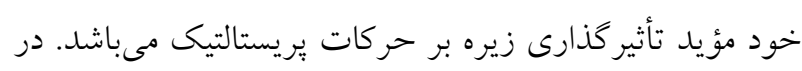

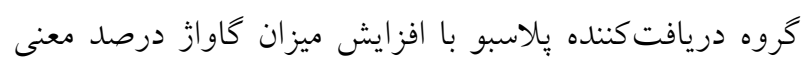

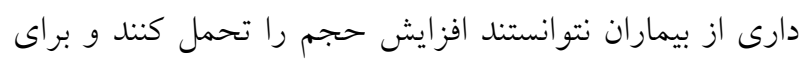

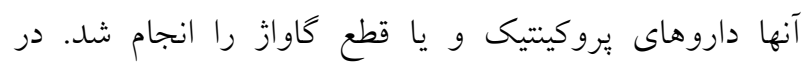

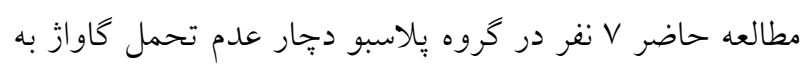

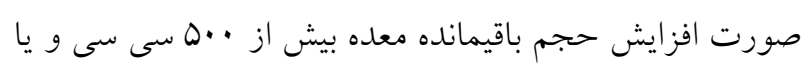

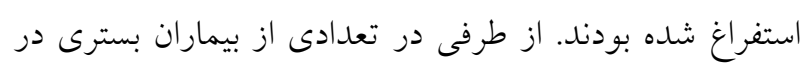

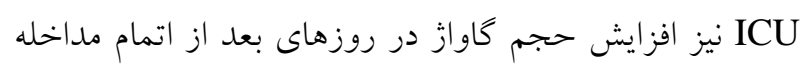

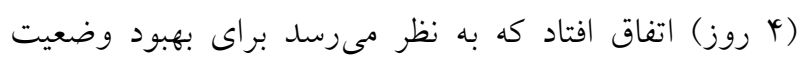


مطالعه به بخش مراقبتهاى ويزه و بيماران ترومايى، امكان

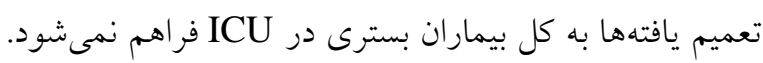

\section{نتيجه گيرى}

از نتايج اين مطالعه مىتوان جهت كاهش حجم باقيمانده

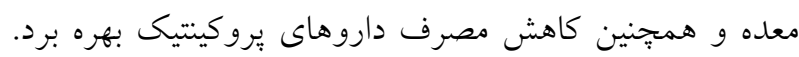

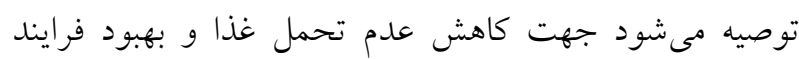

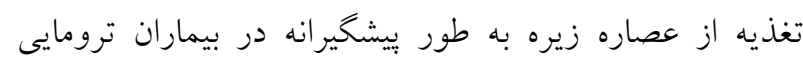

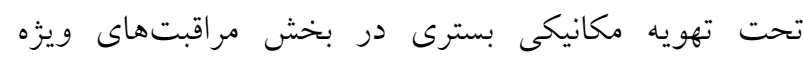

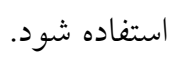

\section{تشكر و قدردانى}

اين مقاله برگرفته شده از باياننامهى كارشناسى ارشد است

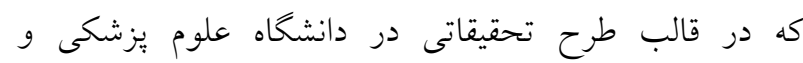

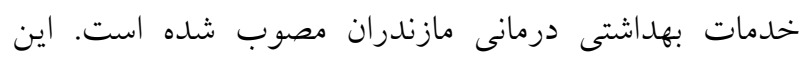
مطالعه يّ از كسب مجوز از كميته اخلاق دانشگاه علوم

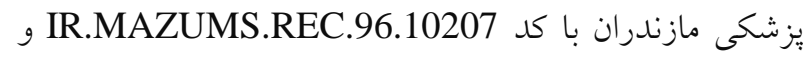

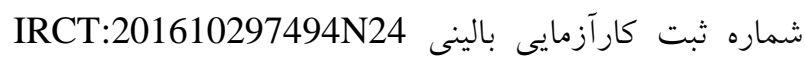

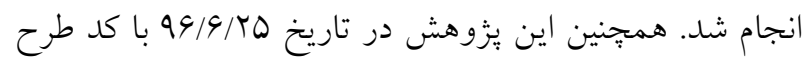
I.T.V

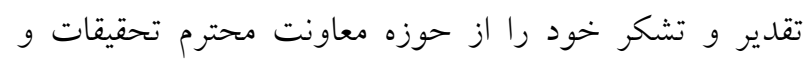

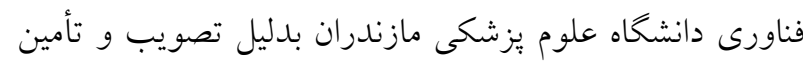

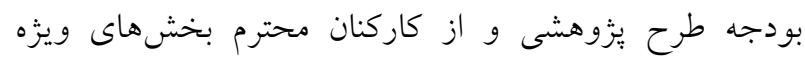

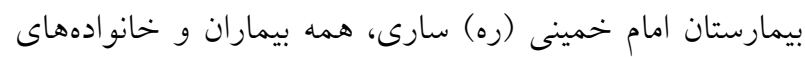

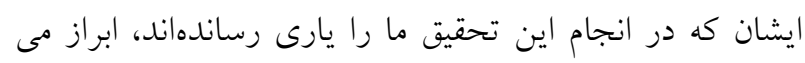
نمايند.

1. Grant $K$ and Thomas R. Prokinetic drugs in the intensive care unit: reviewing the evidence. $J$. the Intensive Care Society 2009; 10 (1): 34-7.

2. Elke G, Felbinger TW and Heyland DK. Gastric residual volume in critically ill patients a
كه در اين مدت حجم گاواز روزانه افزايش مىيابد تا به حد

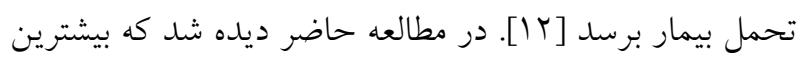

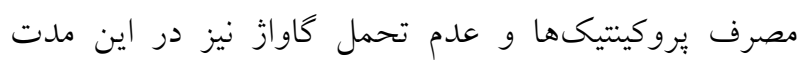

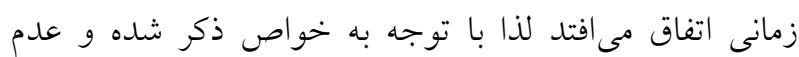

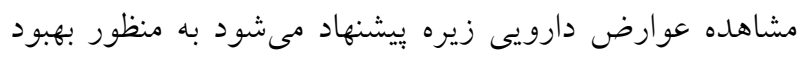

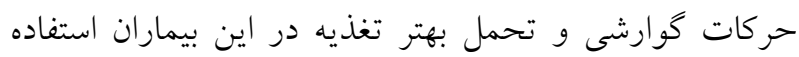

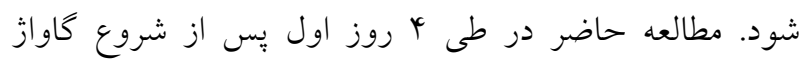

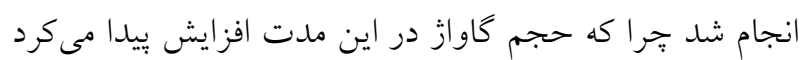

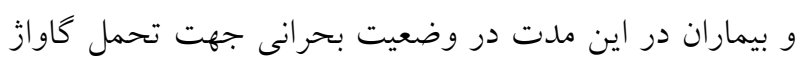

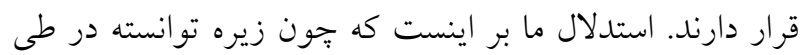

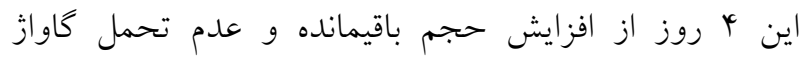

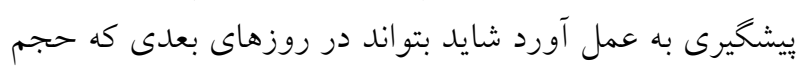

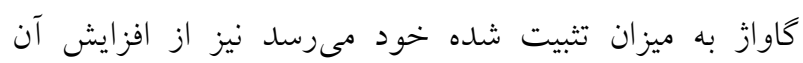

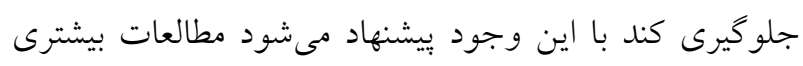

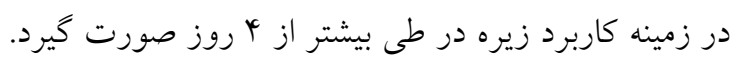

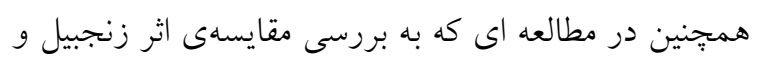

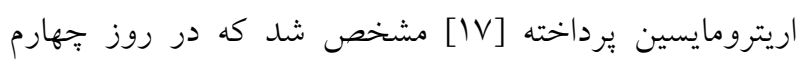

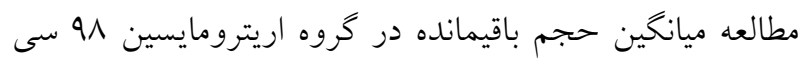

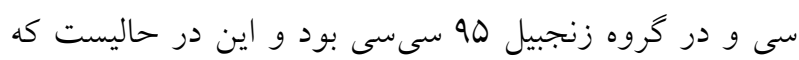

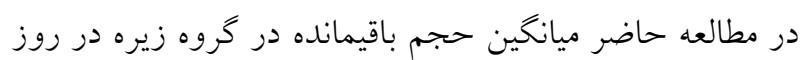

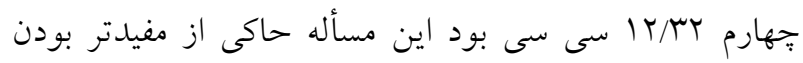

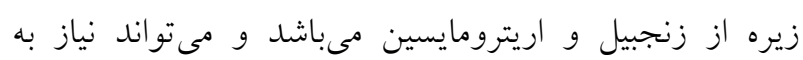
تحقيقات بعدى در زمينه بررسى مقايسهاى زيره و ونسير ساير خياهان

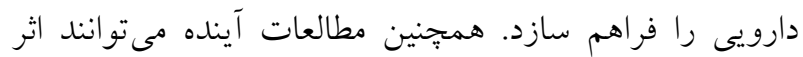

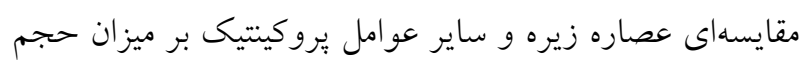

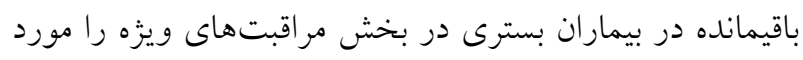

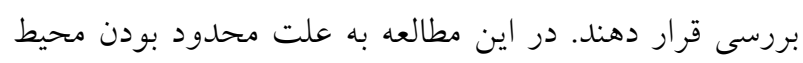

\section{منابع}

dead marker or still alive? Nutrition in Clinical Practice 2015; 30 (1): 59-71.

3. DiMarino AJ, Coben $\mathrm{R}$ and Infantolino $\mathrm{A}$. Sleisenger and Fordtran's Gastrointestinal and Liver Disease Review and Assessment. 9th ed: Elsevier Health Sciences; 2010, pp: 10-98. 
4. Cataldi-Betcher EL, Seltzer MH, Slocum BA and Jones KW. Complications occurring during enteral nutrition support: a prospective study. J. Parenteral and Enteral Nutrition 1983; 7 (6): 546-52.

5. Mentec H, Dupont H, Bocchetti M, Cani $P$, Ponche $\mathrm{F}$ and Bleichner $\mathrm{G}$. Upper digestive intolerance during enteral nutrition in critically ill patients: frequency, risk factors, and complications. Critical Care Medicine 2001; 29 (10): 1955-61.

6. Metheny NA, Schallom L, Oliver DA and Clouse RE. Gastric residual volume and aspiration in critically ill patients receiving gastric feedings. American Journal of Critical Care 2008; 17 (6): 512-9.

7. Hussein HA. The difference between right side and semi recumbent positions after feeding on Gastric Residual Volume among Infants. J. Am. Sci. 2012; 8 (1): 127-32.

8. Landzinski J, Kiser TH, Fish DN, Wischmeyer $\mathrm{PE}$ and MacLaren R. Gastric motility function in critically ill patients tolerant vs intolerant to gastric nutrition. Journal of Parenteral and Enteral Nutrition 2008; 32 (1): 45-50.

9. Miller RD, Eriksson LI, Fleisher LA, WienerKronish JP, Cohen NH and Young WL. Miller's Anesthesia E-Book.5th ed: Elsevier Health Sciences. 2014, pp: 1-817.

10. Alshamsi F, Utgikar R, Almenawer S, Alquraini M, Baw B and Alhazzani W. Postpyloric feeding in critically ill patients: Updated systematic review, meta-analysis and trial sequential analysis of randomized trials. Saudi Critical Care J. 2017; 1 (1): 6-23.

11. Camilleri M, Parkman HP, Shafi MA, Abell TL and Gerson L. Clinical guideline: management of gastroparesis. The American J. Gastroenterol. 2013; 108 (1): 18-37.

12. McClave SA, Taylor BE, Martindale RG, Warren MM, Johnson DR, Braunschweig $\mathrm{C}$ and et al. Guidelines for the provision and assessment of nutrition support therapy in the adult critically ill patient: society of critical care medicine $(\mathrm{sccm})$ and american society for parenteral and enteral nutrition (a.s.p.e.n.). J. Parenteral \& Enteral Nutrition 2016; 40 (2): 159-211.

13. Nguyen NQ and Yi Mei SLC. Current issues on safety of prokinetics in critically ill patients with feed intolerance. Therapeutic Advances in Drug Safety 2011; 2 (5): 197-204.

14. Lewis K, Alqahtani Z, Mcintyre L, Almenawer S, Alshamsi F, Rhodes A and et al. The efficacy and safety of prokinetic agents in critically ill patients receiving enteral nutrition: a systematic review and meta-analysis of randomized trials. Critical Care 2016; 20 (1): 259-71.

15. Al-Snafi AE. Beneficial medicinal plants in digestive system disorders (part 2): plant based review. IOSR Journal of Pharmacy 2016; 6 (7): 85-92.

16. Hekmatafshar M, Bardigorchaei A, Amin G VM, Eshginia S and SAea UNaMJ. The Effect of a Ginger extract on gastric residual volume among mechanically ventilated patients who hospitalized in intensive care unit. The Journal of Urmia Nursing and Midwifery Faculty2012; 10 (3): 360-8. 17. Mirshabani toloti SZ, Bagheri-Nesami M, Shorofi SA and Yazdani-Cherati Amri Male J. Cmparing the effect of Erythromycin and Ginger extract on the gastric residual volume in patients receiving enteral nutrition order in the Intensive Care Unit. Journal of Babol University of Medical Sciences 2017; 19 (1): 14-20.

18. Zarghi A, Kooshki A, Rad M and Tabaraie Y. The Effect of Fenugreek Seeds on Gastric Residual Volume and Respiratory Aspiration in Patients with Mechanical Ventilation. Iranian Journal of Nutrition Sciences \& Food Technol. 2017; 12 (3): 11-8.

19. Yamada $T$, Matsumoto $S$, Matsuda MKA, Shinji S, Yokoyama Y, Takahashi G and et al. The effect of Daikenchuto on postoperative intestinal motility in patients with right-side colon cancer. Surgery Today 2017; 47 (7): 865-71. 
تأثير بيشخيرانه عصاره زيره ...

20. Kawahara H, Mitani $Y$, Nomura $M$, Nose $K$, Yoneda A, Hasegawa $\mathrm{T}$ and et al. Impact of rikkunshito, an herbal medicine, on delayed gastric emptying in profoundly handicapped patients. Pediatric Surgery International. 2009; 25 (11): 987-90.

21. Heacn D. PDR for herbal medicines 4th ed. Montvale United States: Medical Economics Company. 2004, pp: 237-8.

22. Zoorob GK. Herbal preparation to relieve inflammation and smooth muscle contraction. Google patents. 2012, pp: 57-63.

23. Steinegger $E$ and Hansel R. Lehrbuch der Pharmakognosie: auf phytochemischer Grundlage: Springer-Verlag. 2013, pp: 348-82.

24. Bahmani M, Rafieian-Kopaei M, Hassanzadazar H, Saki K, Karamati SA and Delfan B. A review on most important herbal and synthetic antihelmintic drugs. Asian Pacific J. Tropical Medicine 2014; 7 (1): 29-33.

25. Vador N, Jagtap AG and Damle A. Vulnerability of gastric mucosa in diabetic rats, Its pathogenesis and amelioration by Cuminum cyminum. Indian J. Pharmaceutical Sciences 2012; 74 (5): 387-96.

26. Fazel $\mathrm{N}$ and Esmaili $\mathrm{H}$. The effect of cumin oil on the flatulence intensity after cesarean section. Kaums Feyz J. 2005; 9 (3): 8-12 (Persian).

27. Sadeghpour O, Mohammadi A and Aliasl J. Eeffective herbal medicines on nausea and vomiting based on Canon of Avecina. Advances in Environmental Biol. 2015; 9 (3): 557-60.

28. Niaki MT, Atarod Z, Omidvar S, Zafari M, Aghamohammadi A, Asadi T and et al. Comparing the effects of Cumin, Peppermint, and Milk of Magnesia on gastrointestinal complications after caesarean section. Global J. Health Sci. 2016; 8 (12): 78-86.

29. Kumar D, Ganguly K, Hegde HV, Patil PA and Kholkute SD. Spasmolytic effect of traditional herbal formulation on guinea PIG ileum. Ayurveda Integrative Medicine 2015; 6 (3): 194-7.
30. Agah S, Taleb AM, Moeini R, Gorji $\mathrm{N}$ and Nikbakht H. Cumin extract for symptom control in patients with irritable bowel syndrome: a case series. Middle East Journal of Digestive Diseases 2013; 5 (4): 217-22.

31. Yosefi SS, Sadeghpour O, Sohrabvand F, Atarod Z, Askarfarashah M, Ateni TR and et al. Effectiveness of Carum carvi on early return of bowel motility after caesarean section. Euro. J. Exp. Bio. 2014; 4 (3): 258-62.

32. Benzie IF and Wachtel-Galor S. Herbal medicine: biomolecular and clinical aspects. 2ed ed: CRC Press. 2011, pp: 279-80

33. Naghibi SM, Ramezani M, Ayati $\mathrm{N}$ and Zakavi SR. Carum induced hypothyroidism: an interesting observation and an experiment. Daru Journal of Pharmaceutical Sciences 2015; 23 (5): 1-4.

34. Meddah B, Ducroc R, Faouzi MEA, Eto B, Mahraoui L, Benhaddou-Andaloussi A and et al. Nigella sativa inhibits intestinal glucose absorption and improves glucose tolerance in rats. $J$. Ethnopharmacol. 2009; 121 (3): 419-24.

35. Mohammad K and Malek Afzali H. Statistical methods. 16th. Tehran: daricheh no. 2015, pp: 87-8 (Persian).

36. McClave SA, Martindale RG, Vanek VW, McCarthy M, Roberts P, Taylor B and et al. Guidelines for the provision and assessment of nutrition support therapy in the adult critically ill patient: society of critical care medicine $(\mathrm{sccm})$ and american society for parenteral and enteral nutrition (aspen). Journal of Parenteral and Enteral Nutrition 2009; 33 (3): 277-316.

37. Aghili KHorasani SHirazi SM, Ardakani MR, Rahimi R and Farjadmand F. Makhzan advieh. Tehran: Tehran Medical Science Univercity. 2009, pp: 681-682 (Persian).

38. Sakhavar $\mathrm{N}$ and Mirteymouri M. Comparision of Cuminum cyminum with Milk of Magnesia in prevention of gastrointestinal discomforts after emergent cesarean section J. Babol University of Medical Sci. 2009; 10 (6): 42-8 (Persian).

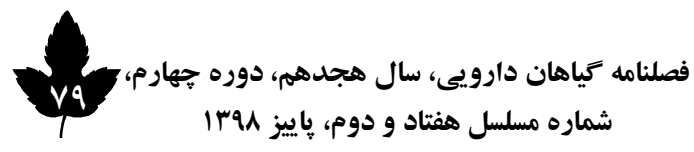


39. Singh $K$ and Goswami T. Mechanical properties of cumin seed (Cuminum cyminum Linn.) under compressive loading. J. Food Engineering 1998; 36 (3): 311-21.

40. Madisch A, Heydenreich C-J, Wieland V, Hufnagel R and Hotz J. Treatment of functional dyspepsia with a fixed peppermint oil and caraway oil combination preparation as compared to cisapride. Arzneimittelforschung 1999; 49 (11): 925-32.

41. Milan KM, Dholakia H, Tiku PK and Vishveshwaraiah P. Enhancement of digestive enzymatic activity by cumin (Cuminum cyminum L.) and role of spent cumin as a bionutrient. Food Chem. 2008; 110 (3): 678-83.

42. Volac J SG. Herbal drugs: Ghoghnoos Publication. 1997, 25-6 (Persian).

43. Nguyen NQ, Chapman M, Fraser RJ, Bryant LK, Burgstad C and Holloway RH. Prokinetic therapy for feed intolerance in critical illness: one drug or two? Critical Care Medicine 2007; 35 (11): 2561-7. 
تأثير بيشخيرانه عصاره زيره ...

\title{
The Prophylactic Effect of Cuminum cyminum Extract on Gastric Residual Volume in Traumatic Patients under Ventilator Hospitalized in Intensive Care Unit
}

\author{
Babaei-Abandansari SR (M.Sc. Student) ${ }^{1}$, Bagheri-Nesami M (Ph.D.) ${ }^{2 *}$, Gholipour-Baradari A \\ (M.D.) $)^{3}$, Yazdani-cherati J (Ph.D.) $)^{4}$, Yosefi SS (Ph.D.) ${ }^{5}$
}

\begin{abstract}
1- Student Research Committee, Mazandaran University of Medical Sciences, Sari, Iran
2- Traditional and Complementary Medicine Research Center, Addiction Institute, Mazandaran University of Medical Sciences, Sari, Iran

3- Department of Anesthesiology, School of Medicine, Mazandaran University of Medical Sciences, Sari, Iran

4- Health Sciences Research Center, Mazandaran University of Medical Sciences, Sari, Iran 5- Department of Traditional Persian Medicine, Traditional and Complementary Medicine, Research Center, Addiction Institute, Mazandaran University of Medical Sciences, Sari, Iran

*Corresponding author: Traditional and Complementary Medicine Research Center, Addiction Institute, Mazandaran University of Medical Sciences, Sari, Iran

Tel: +98-11-33367343, Fax: +98-11-33367342

Email: anna3043@gmail.com
\end{abstract}

\begin{abstract}
Background: Increased Gastric residual volume (GRV) is one of the common problems in ICU.

Objective: The aim of this study was to determine the effect of cumin extract on gastric residual volume in patients with traumatic episodes hospitalized in ICU.

Method: This double-blind randomized clinical trial was conducted on 60 patients traumatic hospitalized in ICU. Patients were randomly assigned to one of two groups: cumin $(n=30)$ and distilled water $(n=30)$. In the intervention group, 6 grams of cumin extract in 3 divided doses were given 50 drops in 30 cc of urban water at 3 times every 8 hours after. The remaining volume was recorded for up to 4 consecutive days and the data were compared in two groups. (IRCT: 201610297494N24).
\end{abstract}

Results: Before the intervention, there was no significant difference between the mean GRV in the cumin group and placebo group $(P=\mathbf{0 . 6 3})$. Comparing the two groups of placebo and placebo, there was no significant difference in the amount of residual stomach in hospitalized patients with ICU on the first day $(P=0.13)$, but on the second, third and fourth days, this difference was significant between the two groups $(p=0.001)$.Comparing the two groups of intervention and placebo, the average volume of residual stomach before and during 4 consecutive days after intervention was significant $(P=0.001)$.

Conclusion: The results of this study showed that cumin extract was effective in decreasing residual stomach volume in hospitalized patients with ICU in comparison with placebo.

Keywords: Cumin, Enteral nutrition, Gastric lavage, Intensive care unit, Residual volume, Ventilated Patients

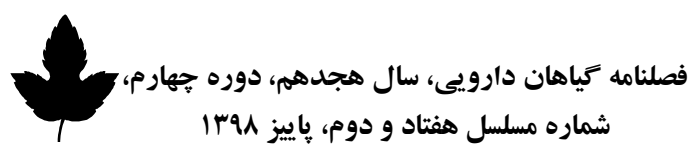

